\title{
Cognitive-Communicative Predictors of Mild Cognitive Impairment: A Systematic Review and Meta-Analysis
}

\author{
Mi Sook Lee ${ }^{1,2}$ \\ 'Department of Audiology \& Speech-Language Pathology, Hallym University of Graduate Studies, Seoul, Korea \\ ${ }^{2}$ HUGS Center for Hearing and Speech Research, Hallym University of Graduate Studies, Seoul, Korea
}

Received: July 28, 2020

Revised: September 29, 2020

Accepted: October 4, 2020

\section{Correspondence:}

Mi Sook Lee, PhD

Department of Audiology \& Speech-

Language Pathology,

Hallym University of Graduate Studies,

427 Yeoksam-ro, Gangnam-gu,

Seoul 06197, Korea

Tel: +82-70-8680-6961

Fax: +82-2-3453-6618

E-mail: mslee2018@hallym.ac.kr

\begin{abstract}
Mild cognitive impairment $(\mathrm{MCl})$ is the preclinical stage and sign of dementia. It is also important for guidance in the prevention and intervention of neurological disease. The purpose of this study was to review literatures on cognitive/communicative and other predictors of $\mathrm{MCl}$ patients systematically, and to propose the evidence-based data including effect sizes of them using a meta-analysis method. Fifty-seven researches published since 2010, meeting the inclusion and exclusion criteria, were entered into the analysis. They were analyzed in a methodological and content level, and the effect sizes were calculated by 3 predictors. Predictive values were pooled from cognitive (10 domains), communicative (9 domains), and other (3 domains). The main findings were as follows. Firstly, the general target population for studies was older adults over the age of 55, and most studies included at least 2 types of predictors. Secondly, average effect sizes of 3 predictors in $\mathrm{MCl}$ were all significant. Thirdly, cognitive predictors like memory and general cognition had significant and high-level effect sizes. Fourthly, communicative predictors including comprehension and word fluency had moderate-level effect sizes significantly. Lastly, all demographic and neuropsychological (age, education, depression) predictors had significant and moderate-level effect sizes. Our results provide the evidence-based information to predict $\mathrm{MCl}$. Especially, specific cognitive and communicative predictors may contribute to increase the diagnostic and prognostic accuracy in $\mathrm{MCl}$. This study is also expected to present clinically available data and increase the effect in intervention for $\mathrm{MCl}$.
\end{abstract}

Key Words: Cognitive, Communicative, Predictors, Meta-analysis, Mild cognitive impairment.

\section{INTRODUCTION}

전 세계적인 치매 인구는 약 5,000만 명에 이른다(Alzheimer's Disease International, 2018). 2050년까지 3초당 1명씩 환 자가 추가되어 1 억 5,200만 명으로 증가할 것이라는 전망도 있 다(Wang et al., 2019). 이 같은 추세를 감안할 때 치매의 전조 증상이자 임상 전(preclinical) 단계에 해당하는 경도인지장애 (mild cognitive impairment, MCI)는 임상적으로 매우 중요한 함의를 갖는다.

$\mathrm{MCI}$ 는 일상 활동에 큰 영향을 주지 않으나 연령 및 교육수 준에 비해 인지 저하가 두드러지는 상태로 임상적 진단 기준이 다양하다(Etgen et al., 2010). Morris et al.(2001)은 1) 기억장 애의 발현, 2) 전반적 인지 및 기능의 보존, 3) 치매로 진단되지

(c) This is an Open Access article distributed under the terms of the Creative Commons Attribution Non-Commercial License (https://creativecommons.org/licenses/by-nc/4.0) which permits unrestricted non-commercial use, distribution, and reproduction in any medium, provided the original work is properly cited.
않은 상태 등을 $\mathrm{MCI}$ 의 진단 기준으로 제시한 바 있다. National Institute on Aging-Alzheimer's Association의 보고서 (Jack et al., 2018)에 따르면, 1) 객관적 인지 평가상 손상 또는 비정상적 범주의 수행력, 2) 인지의 기초선보다 저하된 인지 능 력, 3) 일상 활동을 독립적으로 수행하나 보다 복잡한 활동에 서 인지적 어려움이 감지되며 기능이 경미하게 저하된 상태 등 을 MCI로 진단한다. 이밖에, Diagnostic and Statistical Manual of Mental Disorders, National Alzheimer's Coordinating Center 등이 제시한 기준이나 임상적 증상, 생물학적 구조 등 에 근거해 $\mathrm{MCI}$ 를 진단한다.

이처럼 $\mathrm{MCI}$ 의 진단 기준이 다양하다는 것은 임상적 판단이 매우 중요함을 시사한다. 즉 광범위한 임상적 평가, 임상적 관 찰, 뇌영상 촬영, 생물학적 및 신경심리학적 검사, 일상생활 기 능에 대한 보고 등을 통해 종합적으로 진단할 필요가 있다. 이 는 $\mathrm{MCI}$ 에 대한 중재를 구상하고 효과를 예측하기 위한 근거 자료가 된다는 점에서도 의의가 있다. 따라서 $\mathrm{MCI}$ 의 임상적 양 
상을 영역별로 예측하면 진단적 준거와 중재의 지침으로서 활 용할 수 있다.

$\mathrm{MCI}$ 의 인지적 예측인자는 하위 영역별로 다양한데, 주로 기 억력에 대한 논의가 많다. $\mathrm{MCI}$ 의 주요 진단 근거로서 기억력 손상이 포함되기도 하며(Petersen, 2004), 알츠하이머병(Alzheimer's disease, AD)으로 진행하지 않고 장기간 일정 수준 의 수행력을 유지하는 $\mathrm{MCI}$ 환자는 기억력이 상대적으로 높다 (Alves et al., 2018), 특히 작업기억 용량이 축소되면 인지-언어 기능을 저하시킨다. 이는 새로운 상황에 효율적으로 적응하기 위한 유동성 지능에도 영향을 주며, 정보 처리 속도, 학습, 구 문 이해, 유창성, 담화 산출 등을 방해한다. 주의력은 추론력, 집행기능, 언어 과제 등을 수행하는 데 전제되므로 신경학적 변 화에 민감하다(Facal et al., 2014; Park et al., 2017). 즉 MCI로 인해 전전두피질의 크기와 두께가 축소되면 이러한 기제에도 부정적인 영향을 미친다. 예컨대, 인지-언어 과제를 수행할 때 교차감각적(cross-modal) 방해물이나 불필요한 자극을 억제하 지 못해 지각 및 인지 처리가 크게 제한된다(Alves et al., 2018; Facal et al., 2014). 또 다른 예측인자인 집행기능은 주의력, 작 업기억 등 다른 인지 영역과 함께 복합적인 기능망을 형성하기 때문에, $\mathrm{MCI}$ 로 인해 이러한 기능이 떨어지면 계획과 의사결정, 반응 조율, 행동 억제, 정보 업데이트 등이 어려울 수 있다. 신경 심리 선별 검사나 지능 검사, 다양한 인지 영역이 포함된 치매 검사 등을 통한 전반적 인지 수행력을 $\mathrm{MCI}$ 의 예측인자로 삼기 도 한다. 인지적 수행이 하위 영역 간의 연계성에 기초하므로 전반적 인지 기능은 정상군으로부터 $\mathrm{MCI}$ 를 변별하는 데 유용 한 요인이다.

$\mathrm{MCI}$ 를 예측하는 의사소통적 요인으로 단어유창성과 이름 대기 등 어휘-의미적 측면을 다루는 경우가 많다. 예컨대, 노인 과 $\mathrm{MCI}$ 집단은 어휘-의미적 접근과 반응시간 간에 상관성이 크다(Facal et al., 2016). 이는 처리 자원이 감소할수록 어휘-의 미적 접근의 어려움이 가중되기 때문이다. 이름대기와 어휘 학 습 능력은 $\mathrm{MCI}$ 와 $\mathrm{AD}$ 를 변별하는 진단적 요소라는 보고도 있 다(Hübner et al., 2018). MCI의 의사소통적 예측인자로서 이 해력을 꼽기도 하는데, 이에 활용되는 과제는 연구마다 상이하 다. 즉 복잡한 문자적 및 비문자적 언어, 지시 따르기, 청각적 이해력, 토큰 검사 등을 통해 언어적 해석과 처리를 평가한 후 정상 노인이나 $\mathrm{AD}$ 집단과 변별한다. 이밖에 읽기나 쓰기, 비유 언어, 전반적 언어 등이 $\mathrm{MCI}$ 의 의사소통적 예측 요인으로 활 용되기도 한다.

$\mathrm{MCI}$ 를 예측하는 기타 요인으로 인구통계학적 및 신경심리적 측면이 고려될 수 있다. 예를 들어, 60 세 이상 인구의 $3 \%$, 75 세 이상 노인의 $15 \%$ 가 $\mathrm{MCI}$ 로 진단된다(Wang et al., 2019). 65세 이상 인구 중 $\mathrm{MCI}$ 의 발생률이 인구 1,000 명당 25.9 명에 이른
다는 보고도 있다(Panza et al., 2005). 교육수준도 MCI의 보편 적인 예측인자에 해당한다. 정상적인 인지 수준으로 회복한 $\mathrm{MCI}$ 집단은 상대적으로 연령이 낮고 교육수준은 높게 나타났 다(Xue et al., 2019). Sattler et al.(2012)은 MCI와 AD의 발병 률을 감소시키는 주요 요인으로서 높은 교육수준과 사회경제 적 지위(socioeconomic status, SES)를 꼽았다. 우울증도 $\mathrm{MCI}$ 와 상관성이 높다. 실제로 우울증이 있는 정상군과 $\mathrm{MCI}$ 환자 군은 각각 $\mathrm{MCI}$ 와 치매로 진행할 확률이 높다고 보고된다 (Panza et al., 2010). 특히 시설에 거주하는 MCI 환자 중 약 $44 \%$ 가 우울증을 보이는 것으로 나타났다. $\mathrm{MCI}$ 를 유발하는 신 경병리적 속성이 우울증에 관여할 수 있고, 이는 $\mathrm{MCI}$ 에서 $\mathrm{AD}$ 로의 진행을 예측하는 인자로서 작용하기도 한다(Houde et al., 2008; Panza et al., 2010).

요컨대, $\mathrm{MCI}$ 는 치매의 전조 증상으로서 진단과 예측의 차원 에서 임상적으로 매우 중요하다. 질환의 속성상 진단 기준이 다 양하고 방법론적 범주가 광범위하기 때문에 임상적 판단에 크 게 좌우될 수 있다. 따라서 $\mathrm{MCI}$ 의 변별에 활용할 수 있는 예측 인자를 증거 기반적이고 체계적인 관점에서 제시해야 한다. 이 에 본 연구에서는 2010년 이후의 최근 연구들을 중심으로 $\mathrm{MCI}$ 의 주요 영역별 예측인자를 체계적으로 고찰하고, 메타분 석을 통해 효과크기(effect size) 등 증거 기반적 자료를 제시하 고자 한다. 구체적인 연구 문제는 다음과 같다.

첫째, $\mathrm{MCI}$ 의 주요 예측인자에 관한 연구들을 방법 및 내용 의 질적 측면에서 살펴보고자 한다.

둘째, 예측인자의 각 영역(인지적/의사소통적/기타)에서 평균 효과크기 및 하위 영역별 효과크기를 산출하고 유의미한 예측 인자가 무엇인지를 제시하고자 한다.

\section{MATERIALS AND METHODS}

\section{문헌 수집}

$\mathrm{MCI}$ 의 예측인자를 분석하기 위해 다양한 데이터베이스와 학술지 검색을 통해 문헌을 수집하였다. PudMed, CINAHL Plus with Full Text, MEDLINE, Web of Science, EBSCO, OVID, Scopus 등의 데이터베이스를 활용하였다. 국외 학술지 에 게재된 국내 연구도 분석 대상에 포함하였다. 2020년 6월 16 일자를 기준으로 2010년 이후 게재된 연구에 한해 검색하였다. 구체적인 주제어는 다음과 같다: communication, conversion, detect, diagnose, discriminate, evaluate, language, marker, mild cognitive impairment (MCI), predict (or), prognostic, risk factor. 


\section{대상 연구의 선정}

본 연구를 위한 논문의 선정 기준은 다음과 같다.

첫째, 연구 설계 방법으로서 확률화 배정 연구나 집단 간 비 교 연구로 제한하였다. 동일 집단을 대상으로 한 반복 측정 연 구, 단일사례 연구는 제외하였다. 둘째, 실험 집단의 연구 대상 으로 $\mathrm{MCI}$ 는 포함하였고, 파킨슨병 등 동반 장애가 있는 경우, 주관적 인지-언어장애, 기타 뇌 손상으로 인한 인지장애 등은 제외하였다. $\mathrm{MCI}$ 의 하위 유형으로 기억력의 손상 유무에 따른 기억상실형 $\mathrm{MCI}$ (amnestic MCI, aMCI) 및 비기억상실형 $\mathrm{MCI}$ (nonamnestic MCI, non-aMCI), 손상 영역의 단일성을 기준 으로 단일영역형(single-domain) 및 다영역형(multiple-domain) $\mathrm{MCI}$ 를 모두 포함하였다. 통제 집단은 인지-언어 수행력 이 정상 범주인 경우로 제한하였다. 셋째, 인지적 예측인자로서 주의력, 기억력, 고차원적 인지 등의 하위 영역이나 전반적 인 지 능력을 제시한 연구를 포함하였고, 주관적 인지 호소, 신체 적 및 심리-행동적 수행력에 대한 결과는 배제하였다. 넷째, 의 사소통적 예측인자로서 이해, 이름대기, 읽기 등의 하위 영역이 나 전반적 언어 능력을 포함하였고, 주관적 언어 능력은 제외하 였다. 다섯째, 기타 예측인자로서 연령, 교육 연수, 우울증 등 인 구통계학적 및 신경심리적 측면이 포함되었다. 여섯째, 각 영역 별 수행력의 결과치로서 평균 및 표준편차를 제시한 연구만 선 정하였다.

메타분석을 위해 1차적으로 총 761 개의 논문을 선정하였고, 본 연구의 선정 기준에 따라 704 개의 논문이 제외되어 최종적 으로 총 57 개의 논문을 분석하였다. 이 중 국내 연구는 4 개, 국 외 연구는 53 개였다. 논문 선정 과정은 Figure 1 에 순서도로 제 시하였다.

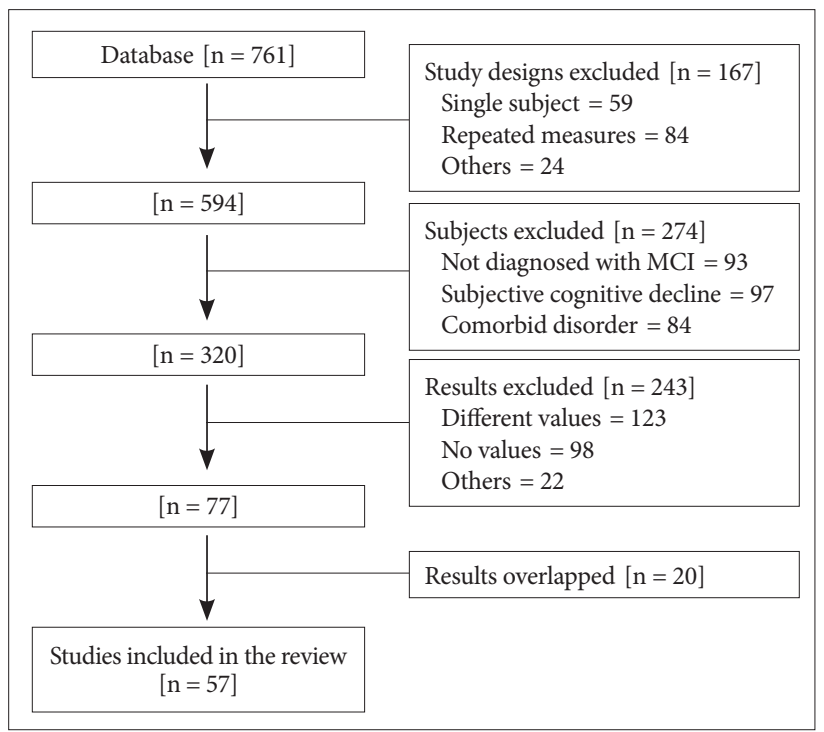

Figure 1. Flow of studies included in the meta-analysis. $\mathrm{MCl}$ : mild cognitive impairment.

\section{자료의 코딩}

분석 대상에 포함된 연구들은 연구자, 출판 연도, 대상자의 특성, 인지적/의사소통적/기타 예측인자의 하위 영역에 따라 코딩되었다. 예측인자는 제시된 통계값(평균/표준편차)으로 분 류하여 코딩하였다. 독립변인은 $\mathrm{MCI}$ 의 유무이고, 종속변인은 $\mathrm{MCI}$ 의 인지적/의사소통적/기타 요인에 대한 수행력이었다. 코 딩된 자료의 수는 총 402 개였는데, 이는 1개 연구에서 2개 이 상의 항목에 대한 결과치를 제시한 연구들이 대부분이었기 때 문이다. 예컨대, Torress et al.(2019)은 언어 이해에 대해 3개의 상이한 항목별로 결과치를 제시하였고, Zhou et al.(2016)의 연 구에서는 기억력과 쓰기에 대해 다수의 결과치를 산정하였다.

코딩 작업은 언어병리학 교수 1 인과 연구 보조원 1 인에 의해 실시되었다. 이들은 1 급 및 2 급 언어재활사 국가자격증을 소지 한 자들로 관련 임상 경력이 7년 이상이었으며, 신경언어장애 에 대한 평가 및 치료 경험이 있었다. 최종 검토 시 이상치나 확 인이 필요한 부분에 대해서는 상호 논의한 후 수정하였다.

\section{연구의 질 및 신뢰도 평가}

연구의 질을 평가하기 위해 Gersten et al.(2005)의 필수적인 질 지표(essential quality indicators)를 사용하여 3점 척도(1 점: 부적절, 2점: 불명확, 3점: 적절)로 측정하였다. 주요 평가 항 목으로는, 연구 대상자의 정보, 집단별 할당 방법, 수행력 평가 의 절차 및 내용, 수행력에 대한 결과 제시 방법 등이었다. 57 개 논문 중 55 개는 평균 3점, 2 개는 2.85점으로 평가되어 논문의 질적 수준이 적절한 것으로 확인되었다.

신뢰도를 평가하기 위해 전체 연구의 $10 \%$ 에 해당하는 논문 을 우선적으로 선택한 후 2인의 평가자가 각각 코딩하고 효과 크기를 산출하였다. 그 결과, 평가자 간 신뢰도는 $100 \%$ 로 산정 되었다.

\section{메타분석}

\section{효과크기의 산출 및 해석}

메타분석을 위한 인지적 예측인자에는 주의력, 계산력, 시지 각력, 지남력, 기억력, 작업기억, 조직화 능력, 추론력, 집행기능, 전반적 인지 등 10 개 하위 영역을 포함하였다. 기억력에는 학습 과 회상(즉각/지연/자유) 능력이 포함되었다. 작업기억은 기억 력의 하위 범주로 분류되기도 하나 본 연구에서는 집행기능 등 다른 영역과의 연계성을 고려하여 개별화하였다. 의사소통적 예측인자는 이해, 구문, 단어유창성, 이름대기, 단어정의, 읽기, 쓰기, 비유언어, 전반적 언어 등 9개 영역을 분석하였다. 단어유 창성은 생성이름대기, 이름대기는 대면이름대기 과제의 수행력 으로 각각 구분하였다. 기타 예측인자로서 연령, 교육 연수, 우 
울증 등 인구통계학적 및 신경심리적 측면의 3 개 영역을 분석 하였다. 이는 대다수의 선행 연구에서 공통적으로 검증된 요인 들로, 사회경제적 지위 등 기타 요소는 수입, 재산, 생활양식, 지 역사회 활동, 정치적 참여, 타인의 평가 등 지표가 다양해 본 연 구의 분석 대상에서 제외하였다.

각 영역별로 수행력을 측정한 결과값을 분석 자료로 사용하 였고, 메타분석용 통계 프로그램인 Comprehensive MetaAnalysis version 3 (Biostat Inc., Englewood, NJ, USA)으로 평균 및 영역별 효과크기를 분석하였다. 집단의 평균 및 표준편 차에 기반하여 효과크기인 Hedges's g값을 산정하였다. 효과크 기는 연구 간의 표본 크기를 고려한 가중평균 효과크기(weight effect size)를 적용하였고, $95 \%$ 신뢰구간을 기준으로 효과크기 의 유의성을 평가하였다.

효과크기를 해석하는 기준으로는 0.20 이하 시 '작은(small) 효과', 0.50 수준 시 ‘중간(medium) 효과', 0.80 이상 시 '큰(large) 효과’로 간주하였다(Lipsey \& Wilson, 2001).

\section{동질성 검증}

개별 연구에서 도출된 효과크기의 통계적 이질성 유무를 확 인하기 위해 동질성 검정을 시행하였다. 그 결과, Table 1과 같이 Q-df $>0, I^{2} \geq 75 \%$ 로 나타나 연구 간의 분산이 실제로 존재할 뿐 아니라 각 효과크기의 이질성이 상당함을 입증하였다(Hig-

Table 1. Verification of homogeneity

\begin{tabular}{ccccc}
\hline $\mathrm{Q}$ & $\mathrm{df}$ & $p$ & $\mathrm{I}^{2}$ & $\mathrm{~T}^{2}$ \\
\hline 1310.58 & 51 & $<0.001$ & 96.11 & 0.32 \\
\hline
\end{tabular}

Q: heterogeneity between studies within domain, $\mathrm{I}^{2}$ : percentage of heterogeneity caused by study differences, $\mathrm{T}^{2}$ : between-studies variance gins \& Green, 2011). 따라서 본 메타분석을 위해 무선효과 모형 (random effect model)을 적용하였다(Borenstein et al., 2009).

\section{출판편의 검증}

메타분석 결과의 타당성을 확보하기 위해 출판편의(publication bias)에 대한 검증을 실시하였다(Rosenthal, 1979). 오류의 존재 유무를 알아보기 위해 Figure 2와 같이 funnel plot을 확 인한 결과 시각적 비대칭성이 관찰되었다. 비대칭의 보정을 위 해 Duval \& Tweedie(2000)의 trim-and-fill 기법을 적용하였 는데, 보정 전의 risk ratio가 43\%인 반면 보정 후에는 $8 \%$ 로 감 소함을 알 수 있었다(Table 2).

통계적 대칭성을 분석하기 위해 Egger의 회귀분석(Egger's regression test) 및 Kendall's tau 검사를 시행하였다. Egger의 회귀분석에서 회귀식 초기값(intercept)은 -2.76으로 통계적 유 의성이 있었다 $(p<0.001$, standard error $=0.45, \mathrm{df}=403.00)$. Kendall's tau 검사 결과에서도 연속성 상관 유무 조건에서 모 든 tau 값이 -0.06 으로 나타나 통계적 유의성을 보였다(z for tau $=1.77, p \leq 0.05)$. 따라서 본 연구를 위해 선정된 논문들이 출판편의상 오류가 있음을 알 수 있었다.

오류의 정도를 살펴보기 위해 Orwin(1983)의 안전계수(failsafe N) 공식을 활용하여 분석한 결과, 안전계수가 609.00으로 대상 연구 수에 비해 누락된 연구의 수가 충분히 큰 것으로 나

Table 2. Statistical adjustment of asymmetry by trim-and-fill

\begin{tabular}{lccc}
\hline & \multicolumn{3}{c}{ Random effect } \\
\cline { 2 - 4 } & Risk ratio & Lower limit & Upper limit \\
\hline Pre-adjustment & 0.43 & 0.51 & 0.36 \\
Post-adjustment & 0.08 & 0.01 & 0.16 \\
\hline
\end{tabular}

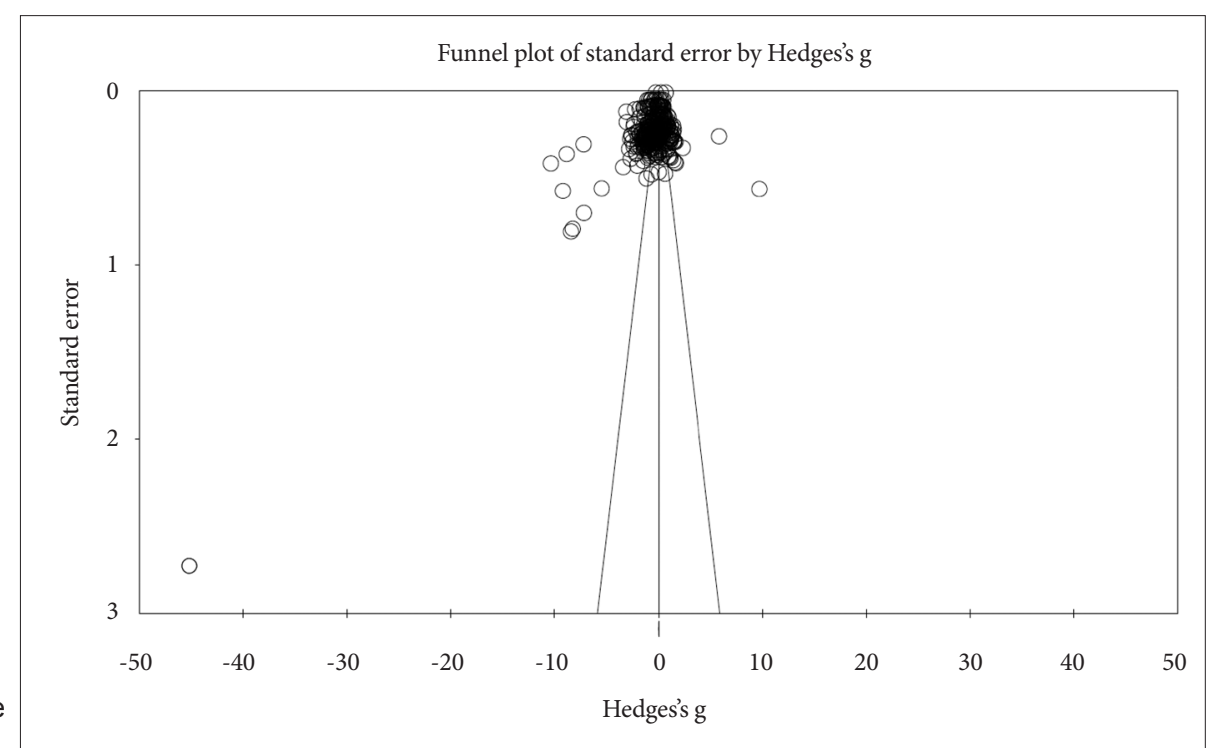


타났다. 궁극적으로 본 연구의 출판편의는 매우 미미한 수준임 을 알 수 있었다.

\section{RESULTS}

\section{연구의 질적 분석}

설계 방법의 측면에서 모든 연구들은 실험 및 통제 집단의 수 행력을 비교해 제시하였다. 연구에 포함된 대상자 수는 6명부터 24,649명까지 매우 다양하였다(Appendix 1). 특히 100명 이하 의 대상자로 구성된 연구가 총 40 개로 대다수를 차지하였다.

연구 대상 중 실험 집단의 평균 연령은 56.9 83.4세, 통제 집 단은 57.3 80.8세로 55세 이상 노년층이 주요 대상자였다. 실험 및 통제 집단의 평균 교육 연수는 각각 4.6 17.1년, 5.1 17.0년 으로 분석되었다. 실험 집단의 $\mathrm{MCI}$ 유형은 $\mathrm{aMCI}, \mathrm{non}-\mathrm{aMCI}$, 단일영역형 및 다영역형 $\mathrm{MCI}$ 로 명시된 연구도 있으나, 대다수 는 구체적인 하위 유형을 언급하지 않았다.

각 연구별로 실험 및 통제 집단의 예측인자를 제시한 결과는 Appendix 1에 제시하였다. 하위 요소는 인지적/의사소통적/기 타 예측인자의 순으로 정리하였다. 한 분야의 예측인자만 포함 된 3개 연구를 제외한 나머지는 최소 2개 분야 이상의 예측인 자를 제시하였다.

예측인자의 수행력을 파악하는 데 활용된 평가도구는 연구 마다 상이하였다. 인지적 예측인자 중 기억력은 Auditory Verbal Learning Test, Rey-Osterrieth Complex Figure의 recall
등, 전반적 인지는 단어-그림 짝짓기, 명령 이행, 문장 처리 등으 로 평가되었다. 의사소통적 예측인자의 이해는 matching wordpicture, commands, sentence processing 등, 단어유창성과 이 름대기는 Verbal Fluency Test (phonological/semantic), Boston Naming Test (BNT) 등이 제시되었다. 기타 예측인자(인구 통계학적 및 신경심리적) 중 우울증은 Geriatric Depression Scale과 Beck's Depression Inventory II가 주로 활용되었다.

\section{효과크기의 분석}

\section{평균 효과크기}

$\mathrm{MCI}$ 환자군과 통제군 간의 3개 예측인자를 비교한 결과 (Table 3), 모든 영역의 평균 효과크기가 유의하게 나타났다. 인 지적 예측인자의 경우 $\mathrm{g}=-0.81(p<0.001), 95 \% \mathrm{CI}=[-0.97$, $-0.66]$ 으로 '큰' 수준이며, 의사소통적 예측인자는 $\mathrm{g}=-0.55$ $(p<0.001), 95 \% \mathrm{CI}=[0.10,0.34]$ 로 '중간' 수준이었다. 기타 예측인자(인구통계학적 및 신경심리적)의 평균 효과크기는 $\mathrm{g}=$ $0.10(p<0.001), 95 \% \mathrm{CI}=[-0.00,0.19]$ 로 '작은' 수준에 해당 하였다.

\section{하위 영역별 효과크기}

3 개 예측인자에서 각 하위 영역별로 효과크기를 비교한 결 과는 Table 4 6에 제시하였다.

인지적 예측변인 중 계산력 $(\mathrm{g}=-6.48, p<0.001)$, 시지각력

Table 3. Mean effect sizes in three factors

\begin{tabular}{lcccccrr}
\hline \multicolumn{1}{c}{ Factor } & $\mathrm{g}$ & $95 \% \mathrm{CI}$ & $\mathrm{K}$ & $\mathrm{Q}$ & $p(\mathrm{Q})$ & $\mathrm{I}^{2}(\%)$ & $\mathrm{FSN}$ \\
\hline Cognitive & -0.81 & {$[-0.97,-0.66]$} & 183 & 7161.86 & $<0.001^{* * *}$ & 97.46 & 725 \\
Communicative & -0.55 & {$[0.10,0.34]$} & 103 & 1840.80 & $<0.001^{* * *}$ & 94.46 & 443 \\
Other & 0.10 & {$[-0.00,0.19]$} & 116 & 5650.18 & $<0.001^{* * *}$ & 97.96 & 1,899 \\
\hline
\end{tabular}

${ }^{*} p<0.05,{ }^{* *} p<0.01,{ }^{* * *} p<0.001$. g: Hedge's g, CI: confidence interval, K: number of the effect size, Q: heterogeneity between studies within domain, $p(\mathrm{Q}): p$-value for heterogeneity, $\mathrm{I}^{2}$ : percentage of heterogeneity caused by study differences, FSN: fail safe $\mathrm{N}$

Table 4. Effect sizes in cognitive factors

\begin{tabular}{|c|c|c|c|c|c|c|c|}
\hline Subdomain & $\mathrm{g}$ & $95 \% \mathrm{CI}$ & $\mathrm{K}$ & Q & $p(\mathrm{Q})$ & $\mathrm{I}^{2}(\%)$ & FSN \\
\hline Attention & -0.51 & {$[-1.08,0.07]$} & 13 & 519.51 & $<0.001^{* * *}$ & 97.69 & 508 \\
\hline Calculation & -6.48 & {$[-9.40,-3.56]$} & 4 & 279.67 & $<0.001^{* * *}$ & 98.93 & 544 \\
\hline Visuoperception & -0.89 & {$[-1.61,-0.17]$} & 13 & 383.48 & $<0.001^{* * *}$ & 96.87 & 875 \\
\hline Orientation & 0.58 & {$[-1.11,2.28]$} & 2 & 20.26 & $<0.001^{* * *}$ & 95.06 & NA \\
\hline Memory & -1.09 & {$[-1.38,-0.80]$} & 56 & 1839.54 & $<0.001^{* * *}$ & 97.01 & 413 \\
\hline Working memory & -0.13 & {$[-0.34,0.08]$} & 17 & 107.40 & $<0.001^{* * *}$ & 85.10 & 350 \\
\hline Organization & -0.58 & {$[-0.95,-0.21]$} & 2 & 0.84 & 0.359 & 0.00 & NA \\
\hline Reasoning & -0.43 & {$[-0.81,-0.04]$} & 2 & 0.05 & 0.831 & 0.00 & NA \\
\hline Executive function & 0.00 & {$[-0.32,0.33]$} & 17 & 216.98 & $<0.001^{* * *}$ & 92.63 & 526 \\
\hline General cognition & -1.04 & {$[-1.35,-0.74]$} & 57 & 2567.79 & $<0.001^{* * *}$ & 97.82 & 407 \\
\hline
\end{tabular}

${ }^{*} p<0.05,{ }^{* *} p<0.01,{ }^{* * *} p<0.001$. g: Hedge's g, CI: confidence interval, K: number of the effect size, Q: heterogeneity between studies within domain, $p(\mathrm{Q})$ : $p$-value for heterogeneity, $\mathrm{I}^{2}$ : percentage of heterogeneity caused by study differences, FSN: fail safe N, NA: not applicable 
Table 5. Effect sizes in communicative factors

\begin{tabular}{|c|c|c|c|c|c|c|c|}
\hline Subdomain & $\mathrm{g}$ & $95 \% \mathrm{CI}$ & $\mathrm{K}$ & Q & $p(\mathrm{Q})$ & $\mathrm{I}^{2}(\%)$ & FSN \\
\hline Comprehension & -0.75 & {$[-1.20,-0.29]$} & 28 & 795.45 & $<0.001^{* * *}$ & 96.61 & 163 \\
\hline Syntax & -0.11 & {$[-0.85,0.64]$} & 2 & 4.26 & $<0.05^{*}$ & 76.52 & NA \\
\hline Word fluency & -0.56 & {$[-0.75,-0.36]$} & 37 & 507.75 & $<0.001^{* * *}$ & 92.91 & 177 \\
\hline Naming & -0.39 & {$[-0.71,-0.08]$} & 12 & 120.05 & $<0.001^{* * *}$ & 90.84 & 512 \\
\hline Word definition & 0.47 & {$[-0.11,1.05]$} & 2 & 6.76 & $<0.001^{* * *}$ & 85.20 & NA \\
\hline Reading & -0.19 & {$[-0.70,0.32]$} & 6 & 51.88 & $<0.001^{* * *}$ & 90.36 & 364 \\
\hline Writing & -0.71 & {$[-1.04,-0.37]$} & 7 & 15.04 & $<0.05^{*}$ & 60.10 & 478 \\
\hline Figurative language & -0.31 & {$[-1.70,1.07]$} & 3 & 47.14 & $<0.001^{* * *}$ & 95.76 & 129 \\
\hline General language & -0.64 & {$[-1.24,0.04]$} & 6 & 54.26 & $<0.001^{* * *}$ & 90.79 & 649 \\
\hline
\end{tabular}

${ }^{*} p<0.05,{ }^{* *} p<0.01,{ }^{* * *} p<0.001$. g: Hedge's g, CI: confidence interval, K: number of the effect size, Q: heterogeneity between studies within domain, $p(\mathrm{Q})$ : $p$-value for heterogeneity, $\mathrm{I}^{2}$ : percentage of heterogeneity caused by study differences, FSN: fail safe N, NA: not applicable

Table 6. Effect sizes in other factors

\begin{tabular}{lcccrrrr}
\hline Subdomain & $\mathrm{g}$ & \multicolumn{1}{c}{$95 \% \mathrm{CI}$} & $\mathrm{K}$ & $\mathrm{Q}$ & $p(\mathrm{Q})$ & $\mathrm{I}^{2}(\%)$ & FSN \\
\hline Age & 0.58 & {$[0.26,0.59]$} & 52 & $1,313.78$ & $<0.001^{* * *}$ & 96.12 & 248 \\
Education & -0.29 & {$[-0.40,-0.17]$} & 48 & 546.35 & $<0.001^{* * *}$ & 91.40 & 95 \\
Depression & 0.22 & {$[0.10,0.34]$} & 16 & 52.36 & $<0.001^{* * *}$ & 71.35 & 349 \\
\hline
\end{tabular}

${ }^{*} p<0.05,{ }^{* *} p<0.01,{ }^{* * *} p<0.001$. g: Hedge’s g, CI: confidence interval, K: number of the effect size, Q: heterogeneity between studies within domain, $p(\mathrm{Q}): p$-value for heterogeneity, $\mathrm{I}^{2}$ : percentage of heterogeneity caused by study differences, FSN: fail safe $\mathrm{N}$

$(\mathrm{g}=-0.89, p<0.001)$, 기억력 $(\mathrm{g}=-1.09, p<0.001)$, 전반적

인지 $(\mathrm{g}=-1.04, p<0.001)$ 는 '큰' 효과크기, 주의력 $(\mathrm{g}=-0.51$, $p<0.001)$ 과 지남력 $(\mathrm{g}=0.58, p<0.001)$ 은 '중간' 수준의 효 과크기, 작업기억 $(\mathrm{g}=-0.13, p<0.001)$ 과 집행기능 $(\mathrm{g}=0.00$, $p<0.001$ )은 '작은 효과크기로서 유의하게 분석되었다. 조직 화 능력 $(\mathrm{g}=-0.58, p=0.359)$ 과 추론력 $(\mathrm{g}=-0.43, p=0.831)$ 의 효과크기는 유의미하지 않았다. 효과크기가 비교적 높은 '기 억력'의 forest plot은 Figure 3에 제시하였다.

의사소통적 예측인자는 모두 유의한 효과크기를 보였다. '중 간 수준의 효과크기는 이해 $(\mathrm{g}=-0.75, p<0.001)$, 단어유창성 $(\mathrm{g}=-0.56, p<0.001)$, 이름대기 $(\mathrm{g}=-0.39, p<0.001)$, 단어 정의 $(\mathrm{g}=0.47, p<0.001)$, 쓰기 $(\mathrm{g}=-0.71, p<0.05)$, 비유언어 $(\mathrm{g}=-0.31, p<0.001)$, 전반적 언어 $(\mathrm{g}=-0.64, p<0.001)$ 등 7개 요인에서 분석되었다. 구문 $(\mathrm{g}=-0.11, p<0.05)$ 과 읽기 $(\mathrm{g}$ $=-0.19, p<0.001)$ 는 '작은' 효과크기를 나타내었다. 가장 높 은 효과크기를 보인 '이해' 요인의 forest plot은 Figure 4에 제 시하였다.

기타 예측인자(인구통계학적 및 신경심리적)는 연령 $(\mathrm{g}=0.58$, $p<0.001)$, 교육 연수( $\mathrm{g}=-0.29, p<0.001)$, 우울증 $(\mathrm{g}=0.22$, $p<0.001)$ 의 순으로 효과크기가 높게 나타났다. 세 요인은 모 두 '중간' 수준의 유의한 효과크기를 보였다. 효과크기가 상대적 으로 높은 '연령' 요인의 forest plot은 Figure 5에 제시하였다. Figures 3 5에서 사용된 문헌은 Appendix 2에 목록화하였다.

\section{DISCUSSIONS}

본 연구는 체계적 고찰과 메타분석을 통해 $\mathrm{MCI}$ 에 대한 인지 적 및 의사소통적, 기타 예측인자를 제시하고자 하였다. 2010년 이후의 57 개 국내외 연구들을 대상으로 방법 및 내용의 질적 특성을 살펴보고, 각 예측인자의 효과크기를 분석하였다.

\section{연구의 질적 분석}

연구의 방법적 측면에서 $\mathrm{MCI}$ 환자군과 통제군은 주로 55 세 이 상의 노년층으로 구성되었다. 평균 교육 연수는 각각 4.6 17.1년, 5.1 17.0년으로 교육수준의 범주가 매우 광범위한 것으로 분석 되었다. 대상자 수는 10 명 이하의 소집단부터 2만 명 이상의 대 규모 연구까지 광범위했으나 전체 연구의 약 70\%는 10 100명 수준에 해당하였다.

일부 연구에서는 $\mathrm{MCI}$ 의 유형을 $\mathrm{aMCI}, \mathrm{non}-\mathrm{aMCI}$, 단일영 역형 및 다영역형 $\mathrm{MCI}$ 로 세분화하였으나(Mohammadi et al., 2018), 하위 유형을 구체화하지 않은 연구가 대다수를 차지하였 다. $\mathrm{MCI}$ 는 기억력의 손상 및 단일성 여부를 기준으로 $\mathrm{aMCI}$ 와 non-aMCI, 단일영역형 $\mathrm{MCI}$ 와 다영역형 $\mathrm{MCI}$ 로 세분화된다 (Fischer et al., 2007). 하위 유형에 따라 인지-언어적 양상이나 신경병리학적 진행 속도가 다르다. 예를 들어, 다영역형 $\mathrm{aMCI}$ 는 $\mathrm{AD}$ 로 진행될 가능성이 높은 반면, non-aMCI는 루이소체 치매(dementia with Lewy bodies), 전두측두엽변성(frontotemporal degeneration) 등 비알츠하이머형 치매로 진행되는 경우가 많다(Folenza et al., 2009). 하위 유형을 세분화하지 않 


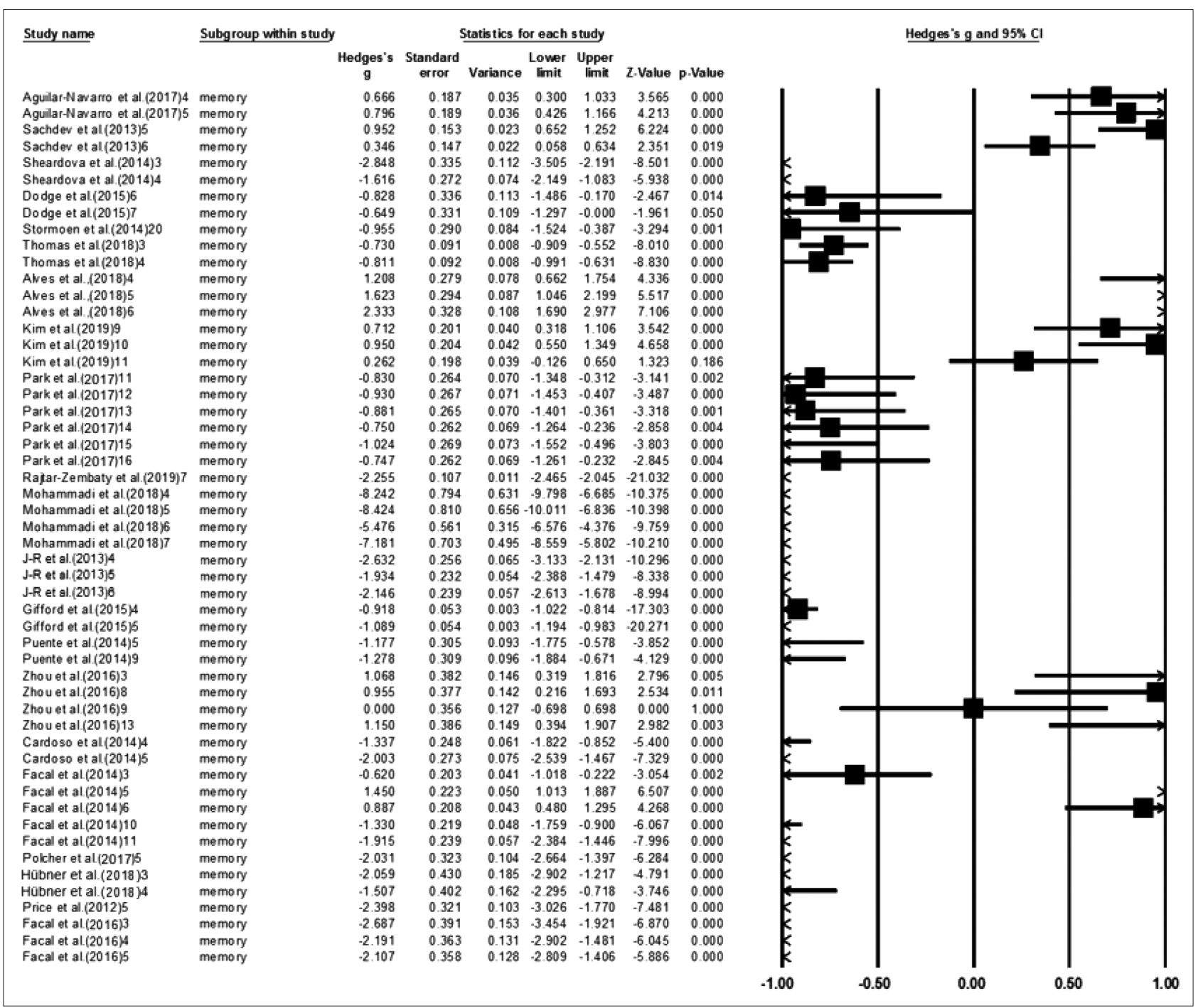

Figure 3. Forest plot of 'memory' factor. Cl: confidence interval.

은 연구들이 대다수이고, 이에 근거해 본 연구가 진행되었으므 로 유형별 분류는 분석 기준에 포함되지 않았다. 따라서 향후 연구에서는 $\mathrm{MCI}$ 의 하위 유형별로 연구 대상이 세분화될 것으 로 보인다.

연구의 내용적 분석 결과, 각 연구에서 도출한 예측인자의 수나 유형은 매우 상이하였다. 인지적 및 의사소통적, 기타 예 측인자 중 일부 혹은 전체가 포함되기도 하고, 생물학적/신체 적/기능적 측면의 인자를 추가적으로 비교한 연구도 있었다. 본 연구에서는 수행력의 통계값으로 평균과 표준편차를 분석 대상으로 삼았으나, Z-score나 예측인자 간 상관계수를 함께 제시한 연구도 있었다. $\mathrm{MCI}$ 의 변별적 진단이 요구되고 이에 따 른 임상적 판단의 중요성이 증대되면서 예측인자의 유형이 보 다 세분화될 필요가 있다. 실제로 최근 연구들에서 $\mathrm{MCI}$ 의 사 회경제적 지표, 심리정서적 요소, 뇌영상 연구에 근거한 생물학
적 지표 등이 제시되는 추세이다(Burton et al., 2018; Chandra et al., 2019; Dodge et al., 2015; Houde et al., 2008).

수행력을 파악하기 위해 활용된 과제의 다양성은 영역별로 분석된 자료 수와 비례하였는데, 이 같은 특성은 인지적 예측 인자에서 가장 두드러졌다. 즉 인지적 예측인자의 하위 유형에 따라 자료 수가 매우 다양하고 수행력을 평가하는 데 활용된 과제가 광범위하였다. 예를 들어, 분석된 자료 수가 많은 기억 력은 어휘 학습, 단어 회상(즉각/지연) 및 재인, 기억하여 그리 기, 논리적 기억 및 이야기 회상 등의 과제로 평가되었다( $\mathrm{Mo}^{-}$ hammadi et al., 2018; Park et al., 2017). 또 집행기능은 스트 룹 검사(Stroop Test), 탑 검사(Tower test), 전반적 집행기능 체 계 검사, 기호잇기 검사(Trail making test) 등이 다양하게 활용 되었다(Arsenault-Lapierre et al., 2012; Manouilidoua et al., 2016). 분석된 자료 수가 적은 지남력, 조직화 능력, 추론력, 계 


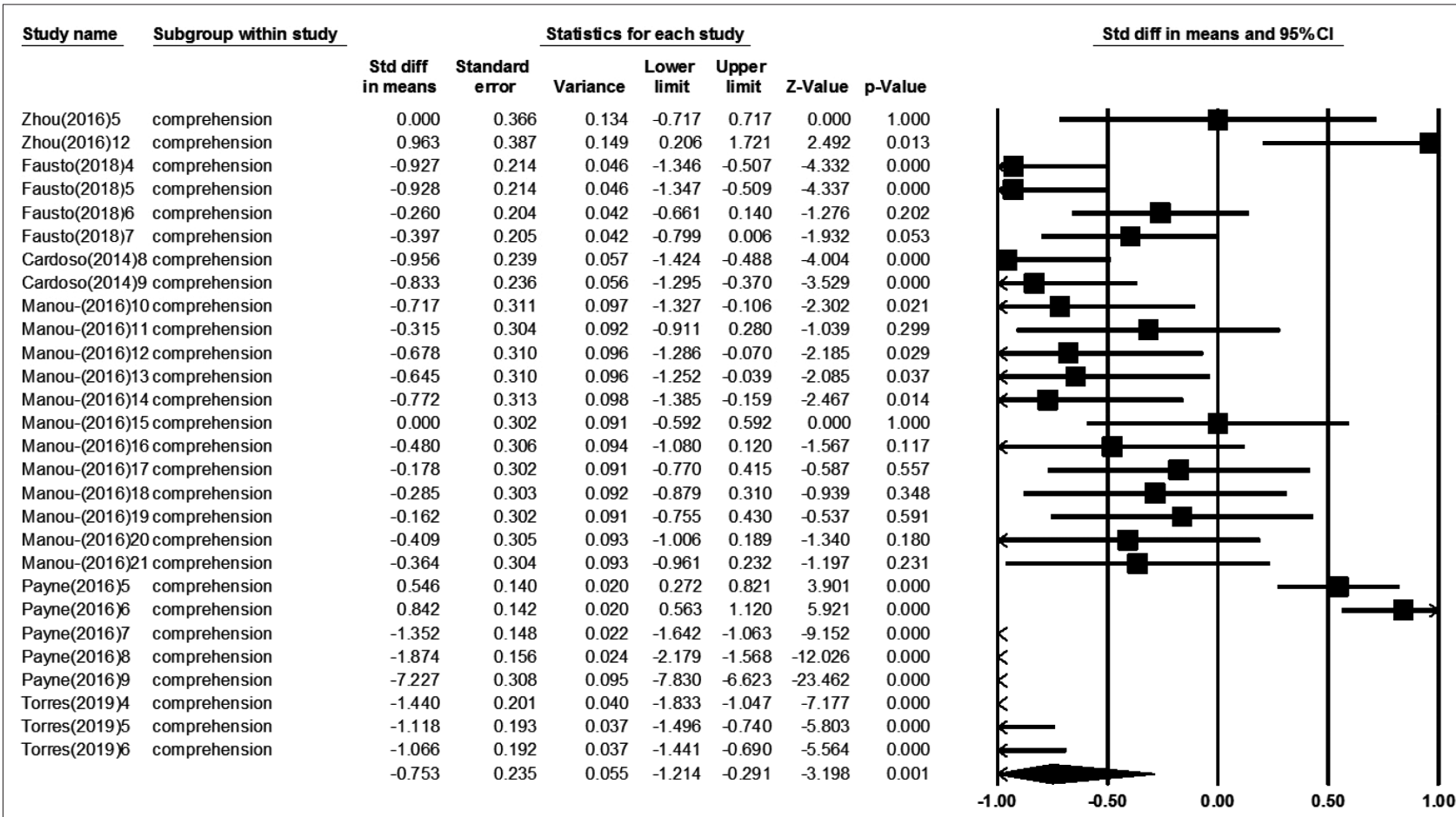

Figure 4. Forest plot of 'comprehension' factor. Cl: confidence interval.

산력 등은 과제의 유형이 비교적 단일하였다.

이에 반해 의사소통적 예측인자는 분석된 자료 수와 과제 유 형 간의 상관성이 비교적 미미하였다. 예컨대, 자료 수가 가장 많은 ‘이해' 요인은 주로 단어 처리나 문장 이해(지시 따르기) 과 제를 통해 평가되었다(Manouilidoua et al., 2016; Payne \& Stine-Morrow, 2016). 대다수의 연구에서 단어유창성은 특정 범주(예: animal)나 음운(예: F/A/S)으로, 이름대기는 특정 평 가도구(예: BNT)로 수행력을 파악하였다. 이러한 경향성은, 다 양화된 신경심리 검사와 영역별 심화검사를 통해 인지 능력을 파악하는 것과 대조적으로 언어 및 의사소통에 대한 세분화된 과제나 도구가 부족한 현실을 반영한다. 반면 대부분의 연구에 서 공통적으로 활용되는 평가의 경우 신뢰도와 타당도가 이미 검증되었고 임상적 활용도가 높다. 이는 여러 연구를 통해 도출 된 결과치가 일관적임을 시사하므로 본 분석 결과의 정확도를 신뢰할 만하다고 간주할 수 있다.

\section{효과크기의 분석}

본 연구에서 3 개 예측인자의 평균 효과크기는 모두 유의하였 고, 인지적 및 의사소통적, 기타(인구통계학적·신경심리적) 예 측인자 순으로 높게 나타났다. 즉 $\mathrm{MCI}$ 를 변별하는 데 있어 3 개 예측인자가 모두 유효하며, 특히 인지적 예측인자는 정상군으 로부터 $\mathrm{MCI}$ 를 변별하는 가장 강력한 예측인자였다. 이는 여러 선행 연구를 통해 규명된 바 있다. 예를 들어, 전반적 인지를 포
함한 인지 기능은 $\mathrm{MCI}$ 를 예측하는 주요 변인으로 작용한다 (Rajtar-Zembaty et al., 2019). 또 초기 단계의 MCI 집단에서 인지 능력은 질환의 진전을 예측하는 가장 민감한 변인으로 제 시된 바 있는데, 이는 생물학적 지표와도 상관성이 크다(Egli et al., 2015). 특히 단어 학습 등의 기억력 과제는 $\mathrm{AD}$ 로의 진행을 예측할 수 있다고 보고된다.

예측인자의 영역별로 효과크기를 분석한 결과, 인지적 예측 변인 중 계산력, 시지각력, 기억력, 전반적 인지는 '큰' 수준, 주 의력과 지남력은 '중간' 수준, 작업기억과 집행기능은 '작은' 수 준의 유의미한 효과크기를 나타내었다. 조직화 능력과 추론력 은 효과크기가 유의미하지 않았는데, 이는 분석 대상에 해당하 는 자료 수가 상대적으로 적은 데 따른 것으로 추측된다.

Rajtar-Zembaty et al.(2019)은 기억력과 전반적 인지가 MCI 와 정상 노인을 변별하는 가장 강력한 독립적 요인으로 제시한 바 있는데, 이는 본 연구 결과와도 일치한다. $\mathrm{MCI}$ 의 진단 기준 에 주관적 기억 호소와 객관적 기억 결함이 포함되기도 하며, 기억력장애가 두드러지는 $\mathrm{aMCI}$ 는 $\mathrm{AD}$ 로 진행될 확률이 높아 임상적으로 주목되는 유형이다(Petersen, 2004). 특히 본 연구 의 기억력에는 단어에 대한 학습이 대다수 포함되었고, 도형, 단어 및 문장, 이야기에 대한 즉각 및 지연, 자유, 단서 회상 등 다양한 회상 과제가 활용되었다. 이는 예측인자뿐 아니라 중재 를 계획할 때 활용할 수 있는 증거 기반적 자료로서 유용하다.

본 연구에서 기억력 및 전반적 인지와 유사한 수준의 높은 


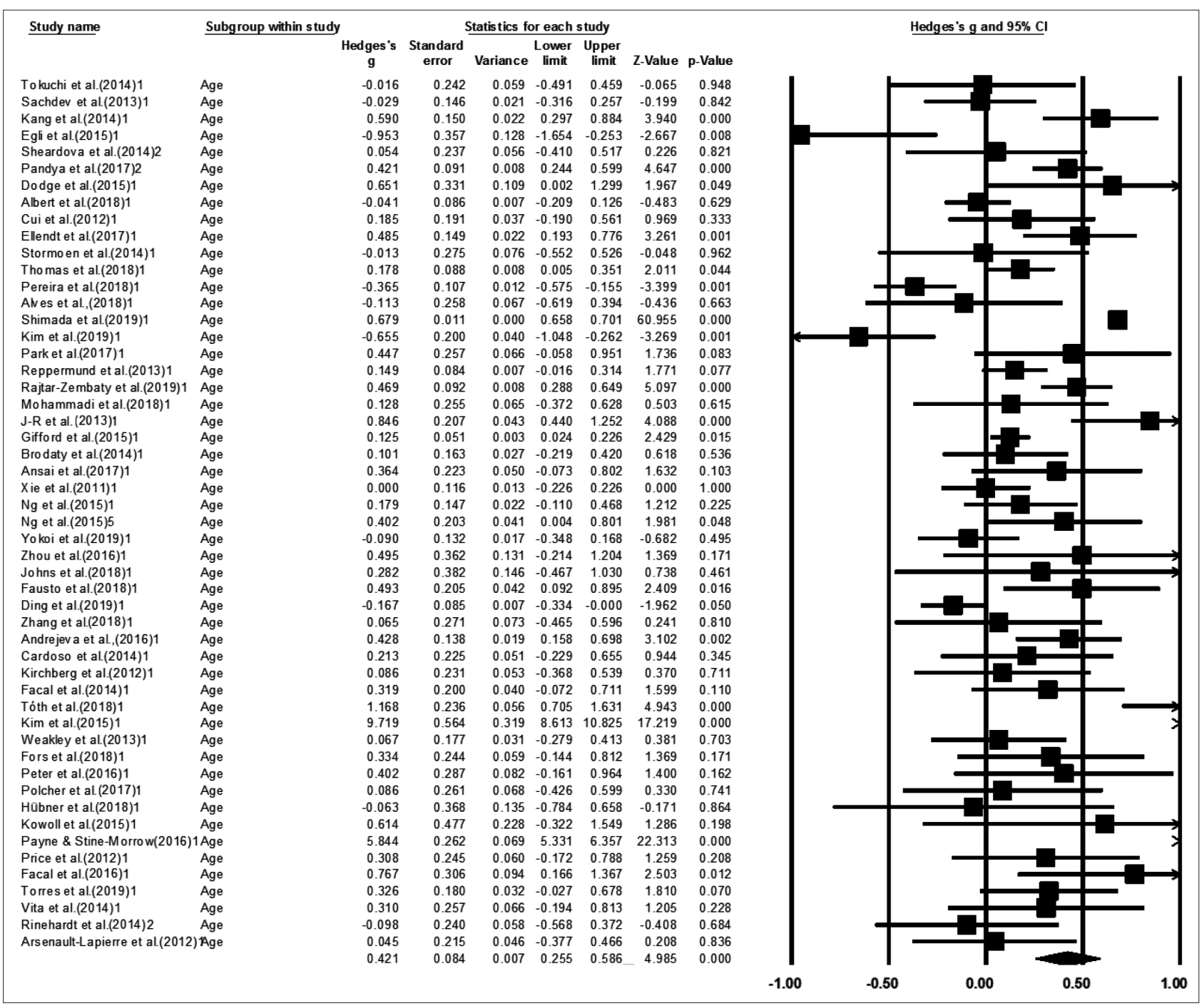

Figure 5. Forest plot of 'age' factor. Cl: confidence interval.

효과크기를 보인 시지각력은 시공간, 시각구성 등의 과제를 통 해 평가되는데, $\mathrm{MCI}$ 에서 결함이 나타나는 보편적 영역 중 하 나이다. 즉 시각 자극의 변별, 새로운 자극의 분석, 친숙한 자극 의 재인, 시각 자극의 이해 등에 관여하는 시지각뿐 아니라 운 동 반응과 결합된 시각구성력이 저하된다. 이로 인해 $\mathrm{MCI}$ 환 자는 Clock Drawing Test와 Raven's Progressive Matrices 등 시공간 과제의 수행력이 낮다. Alves et al.(2018)은 3년 후 AD 로의 진행을 예측하는 데 유효한 지표로서 시공간력을 꼽았다.

작업기억과 집행기능은 전전두피질(prefrontal cortex)과 흑 질선상체(nigrostriatal)의 도파민 신경전달 체계가 관장하는 영역으로, 노화나 신경학적 질환 등 신경학적 변화에 민감하다. $\mathrm{MCI}$ 나 $\mathrm{AD}$ 의 초기부터 두 기능이 손상되므로 일상생활의 과 제를 수행하는 데 복합적인 어려움을 초래한다(Lee \& Kim, $2020 \mathrm{a}, 2020 \mathrm{~b})$. 따라서 집행기능과 연계된 작업기억의 몇몇 하 위 요소는 $\mathrm{MCI}$ 에서 $\mathrm{AD}$ 로의 진전을 예측하는 주요 인자에 해
당한다(Alves et al., 2018; Facal et al., 2014; Park et al., 2017). 본 연구의 메타분석 결과 의사소통적 예측인자의 효과크기 는 모두 유의하였고, 이해, 단어유창성, 이름대기, 단어정의, 쓰 기, 비유언어, 전반적 언어 등이 상대적으로 큰 효과크기를 보 였다. 특히 이해 및 쓰기, 전반적 언어는 의사소통 영역 중 가장 큰 효과크기를 갖는 것으로 분석되었다. 언어 이해는 기억력, 주의력 할당 등과도 연계되는데, 이 같은 인지적 요구가 증가할 수록 제시된 문장을 이해하거나 읽은 내용을 해석하는 데 어려 움을 보인다(Peach \& Shapiro, 2020). MCI의 경우 하위 유형 에 따라 다른 양상을 보이기도 한다. 즉 $\mathrm{aMCI}$ 는 non-aMCI에 비해 언어 이해와 관련된 인지적 처리에 더 큰 결함이 있어 이 해 과제의 수행력이 더 낮다(Payne \& Stine-Morrow, 2016; Zhou et al. 2016). 단어 수준에서는 형태론적 규칙에 대한 지식 은 보존되나 복잡한 비단어를 이해하는 데 어려움을 보인다. 이는 비문법적 형태의 재인을 지연시키는 집행기능의 저하와도 
연관된다(Manouilidoua et al., 2016). 따라서 MCI의 예측인자 로서 ‘이해' 요인의 유효성은 인지적 예측인자, 특히 기억력과 주 의력, 집행기능의 영향도 크게 작용한다. 쓰기의 경우 단어나 과제의 유형과 같은 다양한 변인이 작용하나, $\mathrm{MCI}$ 로 인해 구 문적으로 단순하고 정보 단위가 적은 문장을 산출하는 경향이 있다. 글자상 오류도 정상군과의 변별에 활용될 수 있다.

어휘-의미적 측면인 단어유창성과 이름대기도 신경학적 변 화에 민감한 영역이다. 이들은 의미기억과 상관성이 높고, 의미 적·음운적 및 글자 체계로 조직화되어 상호 연계된 네트워크 를 형성하기 때문이다(Hübner et al., 2018; Lee \& Kim, 2020b). 따라서 단어유창성과 이름대기의 효과크기는 기억력의 효과크기가 유효한 것과도 크게 관련된다. 예를 들어, 대면이름 대기를 수행할 때 먼저 그림 자극이 의미 영역을 활성화한 후 단어를 산출하기 위해 음운 표상을 자극한다(Peach \& Shapiro, 2020). 이때 어휘의 빈도, 어휘 사용의 최신성, 신경학적 변 화 등이 영향을 미친다. $\mathrm{MCl}$ 와 $\mathrm{AD}$ 는 의미 체계 자체의 결함 이나 접근 능력의 저하로 의미적 오류가 빈번해진다(Hübner et al., 2018; Zhou et al., 2016). 단어정의 과제에서 MCI의 수행력 이 낮은 것도 이와 동일한 맥락으로 해석될 수 있다(Lee \& Kim, 2020b).

메타분석 결과에서 비유언어의 효과크기는 다른 의사소통 영역에 비해 상대적으로 낮으나 유의미한 것으로 분석되었다. 이는 집행기능의 역할과 연계된다. 비유언어는 문자 그대로가 아닌 화용적 추론에 기반하는데, $\mathrm{MCI}$ 로 인해 집행기능이 저하 되면 의미적 부호화를 반복함으로써 억제 기능이 제한된다 (Lee \& Kim, 2020b). 이로 인해 문자적 해석과 비문자적 해석 간의 전환이 느리고, 드러나지 않은 의미에 대한 추론적 실행 이 어려워진다(Alves et al., 2018).

본 연구에서 인구통계학적 및 신경심리적 측면의 기타 예측 인자는 연령, 교육 연수, 우울증 순으로 높았고, 모두 '중간' 수 준의 유의미한 효과크기를 보였다. $\mathrm{MCI}$ 이후 정상적인 인지의사소통 수준으로 회복하는 데 초점을 둔 연구들은 예측인자 의 규명이 가역성 비율(reversion rate)을 증진한다는 점에서 중 요하다고 강조하였다(Xue et al., 2019). 이는 $\mathrm{AD}$ 로의 진행을 예방하는 차원에서도 매우 유의미하다. 특히 더 적은 연령과 높은 교육수준은 $\mathrm{MCI}$ 의 회복에 결정적으로 기여한다(Sattler et al., 2012; Xue et al., 2019). 반면 연령이 높거나 교육수준이 낮을수록 $\mathrm{AD}$ 로 진행할 위험이 증가한다. 높은 교육수준은 인 지 보존능력(cognitive reserve)의 주요 하위 영역으로서 인지의사소통 기능을 보존하는 데 기여한다고 알려져 있다(Lee, 2015). 또 문해 능력을 보존함으로써 건강 관련 지식을 이해하 고 활용하는 데 유리할 뿐 아니라 건강한 생활양식과 $\mathrm{SES}$ 를 유지할 가능성이 높다(Houde et al., 2008).
우울증도 신경학적 질환의 위험 요인 중 하나일 수 있다. 신 경학적 질환과 우울증의 동반은 생물학적, 감정적, 인지적 증상 간의 복잡한 상호작용을 반영한다. 우울증 자체가 $\mathrm{MCI}$ 에서 $\mathrm{AD}$ 로의 진행을 예측하지는 않으나 2 3년간 지속되는 우울장애는 $\mathrm{AD}$ 로의 진행 가능성을 증가시킬 수 있다(Houde et al., 2008; Park et al., 2017). 특히 aMCI에 동반된 지속적인 우울 증상은 인지 저하를 더욱 심화시킨다. 우울감(melancholy) 등의 하위 증상은 특정 신경전달물질 체계나 해부학적 네트워크와 연관 되어 $\mathrm{AD}$ 로의 진행을 가중시킨다는 연구 결과도 있다(Houde et al., 2008).

요컨대, 본 연구는 메타분석을 활용하여 $\mathrm{MCI}$ 를 예측하는 인 지적 및 의사소통적 요인과 기타 요인을 도출한 후 질적 및 양 적 분석 결과를 체계적으로 논의하였다. 이는 $\mathrm{MCI}$ 를 변별적으 로 진단하기 위한 증거 기반적 지침으로서 활용될 수 있을 것이 다. 또 인지-의사소통 양상의 심화나 $\mathrm{AD}$ 로의 진행을 예방하는 데 기여할 것이다. 궁극적으로, $\mathrm{MCI}$ 전후의 중재 과정에서 인 지-의사소통적 예측인자와의 연계성을 고려한 과제를 구상하 고 중재의 효과성을 제고하기 위한 기초로 삼을 수 있을 것이다. 본 연구의 제한점은 다음과 같다. 첫째, 본 메타분석은 데이 터베이스 및 학술지에 게재된 연구만을 대상으로 하였다. 따라 서 출판편의에 대한 검증을 거쳤음에도 '회색 문헌(grey publications)'이나 '비관행적 문헌(non-conventional publication)'을 포함하지 않은 데 따른 편향성을 완전히 배제할 수 없을 것이 다. 둘째, 본 연구에서 지남력, 조직화 능력 등의 인지적 요인과 구문, 비유언어 등의 의사소통적 요인은 분석된 자료 수가 5 개 미만으로 비교적 적은 편이었다. 이는 각 효과크기의 신뢰도와 타당도에 영향을 미칠 수 있을 것이다. 셋째, $\mathrm{MCI}$ 는 하위 유형 에 따라 인지-의사소통 양상이 다르게 나타난다. 후속 연구를 통해 $\mathrm{aMCI}$ 및 non-aMCI, 단일 및 다영역형 $\mathrm{MCI}$ 등 하위 유 형별로 예측인자를 제시하거나 비교할 필요가 있을 것이다. 넷 째, 본 연구는 국외 연구를 주요 분석 대상으로 삼았고 국내의 경우 해외 학술지에 게재된 연구로 제한하였다. 이는 본 연구의 선정 기준에 부합하는 국내 연구가 양적으로 매우 부족한 현실 을 감안한 것이다. 향후에는 선정 기준의 확대, 방법론적 전환, 문헌의 다양화 등을 통해 국내 연구에 중점을 둔 분석을 시도 할 필요가 있다.

중심 단어 : 인지적·의사소통적·예측인자·메타분석·경도인지 장애.

\section{Ethical Statement}

We explained exactly the purpose and process of this study to all participants in advance. And they agreed to participate in it. 


\section{Acknowledgments}

The authors thank to the participants.

\section{Declaration of Conflicting Interests \\ There are no conflict of interests.}

\section{Funding}

This work was supported by the Ministry of Education of the Republic of Korea and the National Research Foundation of Korea (NRF-2020S1 A5A8040953).

\section{ORCID iDs}

Mi Sook Lee

\section{REFERENCES}

Alves, L., Cardoso, S., Maroco, J., de Mendonça, A., Guerreiro, M., \& Silva, D. (2018). Neuropsychological predictors of long-term (10 Years) mild cognitive impairment stability. Journal of Alzheimer's Disease: $J A D, 62(4), 1703-1711$.

Alzheimer's Disease International. (2018). World Alzheimer Report 2018. London: Alzheimer's Disease International.

Arsenault-Lapierre, G., Bergman, H., \& Chertkow, H. (2012). Word reading threshold and mild cognitive impairment: a validation study. $B M C$ Geriatrics, 12, 38.

Borenstein, M., Hedges, L. V., Higgins, J. P., \& Rothstein, H. R. (2009). Introduction to Meta-Analysis. Chichester: John Wiley \& Sons.

Burton, R. L., O'Connell, M. E., \& Morgan, D. G. (2018). Cognitive and neuropsychiatric correlates of functional impairment across the continuum of no cognitive impairment to dementia. Archives of Clinical Neuropsychology, 33(7), 795-807.

Chandra, A., Valkimadi, P., Pagano, G., Cousins, O., Dervenoulas, G., \& Marios, P. for the Alzheimer's Disease Neuroimaging Initiative. (2019). Applications of amyloid, tau, and neuroinflammation PET imaging to Alzheimer's disease and mild cognitive impairment. Human Brain Mapping, 40(18), 5424-5442.

Dodge, H. H., Mattek, N., Gregor, M., Bowman, M., Seelye, A., Ybarra, O., et al. (2015). Social markers of mild cognitive impairment: Proportion of word counts in free conversational speech. Current Alzheimer Research, 12(6), 513-519.

Duval, S. \& Tweedie, R. (2000). A nonparametric "trim and fill" method of accounting for publication bias in meta-analysis. Journal of the American Statistical Association, 95(449), 89-98.

Egli, S. C., Hirni, D. I., Taylor, K. I., Berres, M., Regeniter, A., Gass, A., et al. (2015). Varying strength of cognitive markers and biomarkers to predict conversion and cognitive decline in an early-stage-enriched mild cognitive impairment sample. Journal of Alzheimer's Disease, 44(2), 625-633.

Etgen, T., Sander, D., Bickel, H., Sander, K., \& Förstl, H. (2010). Cognitive decline: The relevance of diabetes, hyperlipidaemia and hypertension. The British Journal of Diabetes and Vascular Disease, 10(3), 115-122.

Facal, D., Juncos-Rabadán, O., Guardia-Olmos, J., \& Pereiro, A. X. (2016). Temporal changes in semantic and lexical access related to mild cognitive impairment. Aging Clinical and Experimental Research, 28, 497504.

Facal, D., Juncos-Rabadán, O., Pereiro, A. X., \& Lojo-Seoane, C. (2014). Working memory span in mild cognitive impairment. Influence of processing speed and cognitive reserve. International Psychogeriatrics, 26(4), 615-625.

Fischer, P., Jungwirth, S., Zehetmayer, S., Weissgram, S., Hoenigschnabl, S., Gelpi, E., et al. (2007). Conversion from subtypes of mild cognitive impairment to Alzheimer dementia. Neurology, 68(4), 288-291.

Forlenza, O. V., Diniz, B. S., Nunes, P. V., Memória, C. M., Yassuda, M. S., \& Gattaz, W. F. (2009). Diagnostic transitions in mild cognitive im-

pairment subtypes. International Psychogeriatrics, 21(6), 1088-1095.

Gersten, R., Fuchs, L. S., Compton, D., Coyne, M., Greenwood, C., \& Innocenti, M. S. (2005). Quality indicators for group experimental and quasi-experimental research in special education. Exceptional Children, 71(2), 149-164.

Higgins, J. P. T., \& Green, S. (2011, March). Cochrane Handbook for Systematic Reviews of Interventions Version 5.1.0. The Cochrane Collaboration. Retrieved from https://handbook-5-1.cochrane.org/.

Houde, M., Bergman, H., Whitehead, V., \& Chertkow, H. (2008). A predictive depression pattern in mild cognitive impairment. International Journal of Geriatric Psychiatry, 23(10), 1028-1033.

Hübner, L. C., Loureiro, F., Tessaro, B., Siqueira, E. C. G., Jerônimo, G. M., Gomes, I., et al. (2018). Naming and verbal learning in adults with Alzheimer's disease, mild cognitive impairment and in healthy aging, with low educational levels. Arquivos de Neuro-Psiquiatria, 76(2), 9399.

Jack, C. R., Jr, Bennett, D. A., Blennow, K., Carrillo, M. C., Dunn, B., Haeberlein, S. B., et al. (2018). NIA-AA Research Framework: toward a biological definition of Alzheimer's disease. Alzheimer's and Dementia: The Journal of the Alzheimer's Association, 14(4), 535-562.

Lee, M. S. (2015). Meta-analysis of correlation between cognitive-linguistic ability and cognitive reserve in normal aging. The Journal of the Korea Contents Association, 15(11), 359-373.

Lee, M. S. \& Kim, B. S. (2020). Effects of working memory intervention on language production by individuals with dementia. Neuropsychological Rehabilitation. [Epub]. https://doi.org/10.1080/09602011.2020. 1789479.

Lee, M. S. \& Kim, B. S. (2020). Higher order cognition and communication: A preliminary study for the development of brief test of cognitive-communication disorders. Audiology and Speech Research, 16(3), 236-244.

Lipsey, M. W. \& Wilson, D. B. (2001). Practical Meta-Analysis. Thousand Oaks, CA: SAGE Publications.

Manouilidou, C., Dolenc, B., Marvin, T., \& Pirtošek, Z. (2016). Processing complex pseudo-words in mild cognitive impairment: The interaction of preserved morphological rule knowledge with compromised cognitive ability. Clinical Linguistics and Phonetics, 30(1), 49-67.

Mohammadi, A., Kargar, M., \& Hesami, E. (2018). Using virtual reality to distinguish subjects with multiple- but not single-domain amnestic mild cognitive impairment from normal elderly subjects. Psychogeriatrics, 18(2), 132-142.

Morris, J. C., Storandt, M., Miller, J. P., McKeel, D. W., Price, J. L., Rubin, E. $\mathrm{H}$., et al. (2001). Mild cognitive impairment represents early-stage Alzheimer disease. Archives of Neurology, 58(3), 397-405.

Orwin, R. G. (1983). A fail-safe N for effect size in meta-analysis. Journal of Educational Statistics, 8(2), 157-159.

Panza, F., D'Introno, A., Colacicco, A. M., Capurso, C., Del Parigi, A., Caselli, R. J., et al. (2005). Current epidemiology of mild cognitive impairment and other predementia syndromes. The American Journal of Geriatric Psychiatry, 13(8), 633-644.

Panza, F., Frisardi, V., Capurso, C., D’Introno, A., Colacicco, A. M., Imbimbo, B. P., et al. (2010). Late-life depression, mild cognitive impairment, and dementia: Possible continuum? The American Journal of Geriatric Psychiatry, 18(2), 98-116.

Park, J. H., Park, H., Sohn, S. W., Kim, S., \& Park, K. W. (2017). Memory performance on the story recall test and prediction of cognitive dysfunction progression in mild cognitive impairment and Alzheimer's dementia. Geriatrics and Gerontology International, 17(10), 1603-1609.

Payne, B. R. \& Stine-Morrow, E. A. (2016). Risk for mild cognitive impairment is associated with semantic integration deficits in sentence processing and memory. The Journals of Gerontology: Series B, 71(2), 243253.

Peach, R. K. \& Shapiro, L. P. (2020). Cognition and Acquired Language Disorders: An Information Processing Approach (Lee, M. S. \& Kim, S. R., Trans.). (1st ed.). Seoul: Hakjisa. 
Petersen R. C. (2004). Mild cognitive impairment as a diagnostic entity. Journal of Internal Medicine, 256(3), 183-194.

Rajtar-Zembaty, A., Rajtar-Zembaty, J., Sałkowski, A., Starowicz-Filip, A., \& Skalska, A. (2019). Global cognitive functioning and physical mobility in older adults with and without mild cognitive impairment: Evidence and implications. Folia medica Cracoviensia, 59(1), 75-88.

Rosenthal, R. (1979). The "file drawer problem" and tolerance for null results. Psychological Bulletin, 86(3), 638-641.

Sattler, C., Toro, P., Schönknecht, P., \& Schröder, J. (2012). Cognitive activity, education and socioeconomic status as preventive factors for mild cognitive impairment and Alzheimer's disease. Psychiatry Research, 196(1), 90-95.

Torres, V. L., Rosselli, M., Loewenstein, D. A., Curiel, R. E., Vélez Uribe, I., Lang, M., et al. (2019). Types of errors on a semantic interference task in mild cognitive impairment and dementia. Neuropsychology, 33(5), 670-684.

Wang, J., Wang, L., Zhou, X., Wen, X., \& Zhen, X. (2019). Risk factors for predicting progression from normal cognition to mild cognitive impairment: Protocol for a systematic review and meta-analysis of cohort studies. BMJ Open, 9(6), e027313.

Xue, H., Hou, P., Li, Y., Mao, X., Wu, L., \& Liu, Y. (2019). Factors for predicting reversion from mild cognitive impairment to normal cognition: A meta-analysis. International Journal of Geriatric Psychiatry, 34(10), 1361-1368.

Zhou, J., Jiang, B., Huang, X. H., Kong, L. L., \& Li, H. L. (2016). Characteristics of agraphia in Chinese patients with Alzheimer's disease and amnestic mild cognitive impairment. Chinese Medical Journal, 129(13), 1553-1557. 


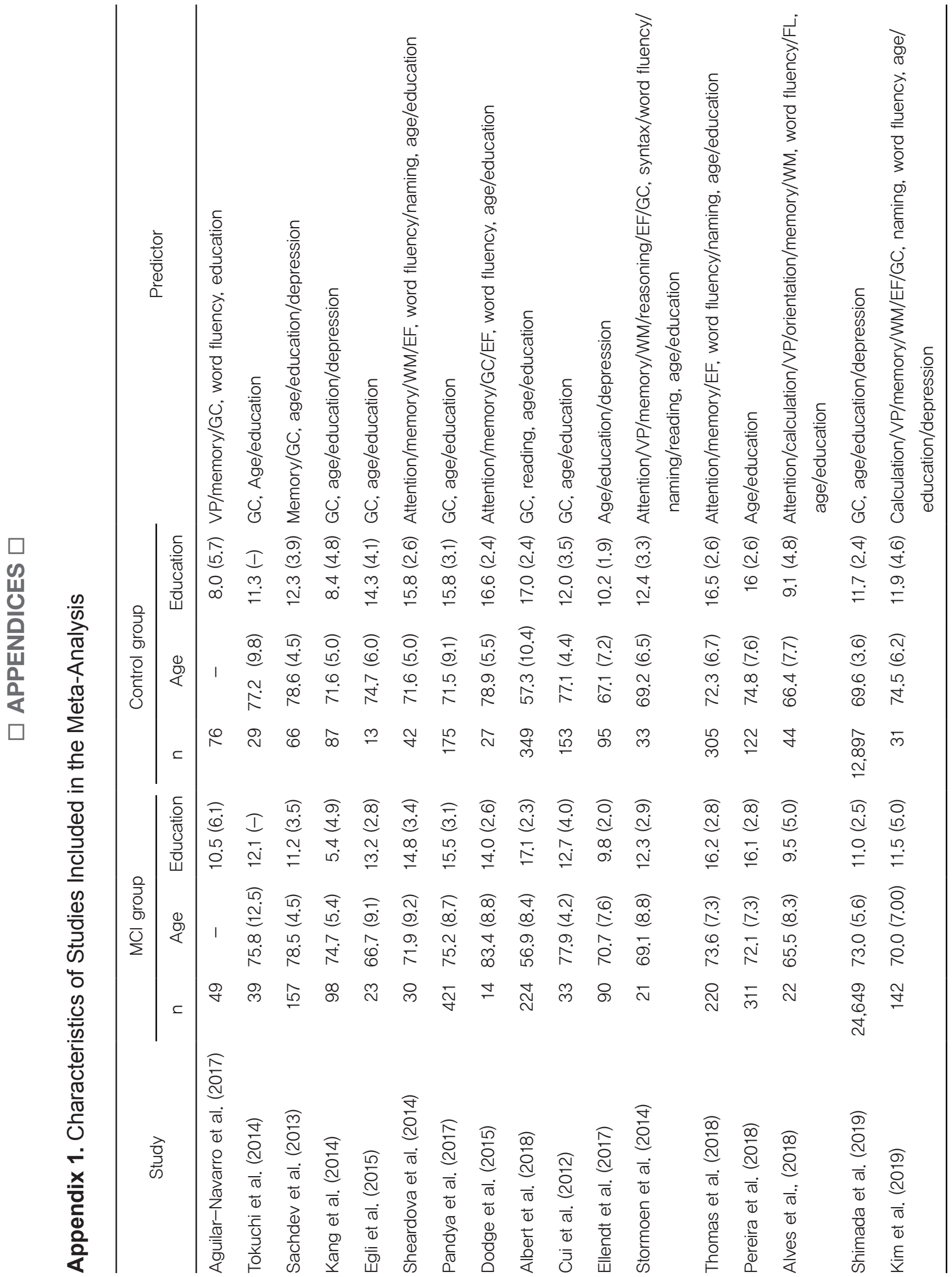


M Lee

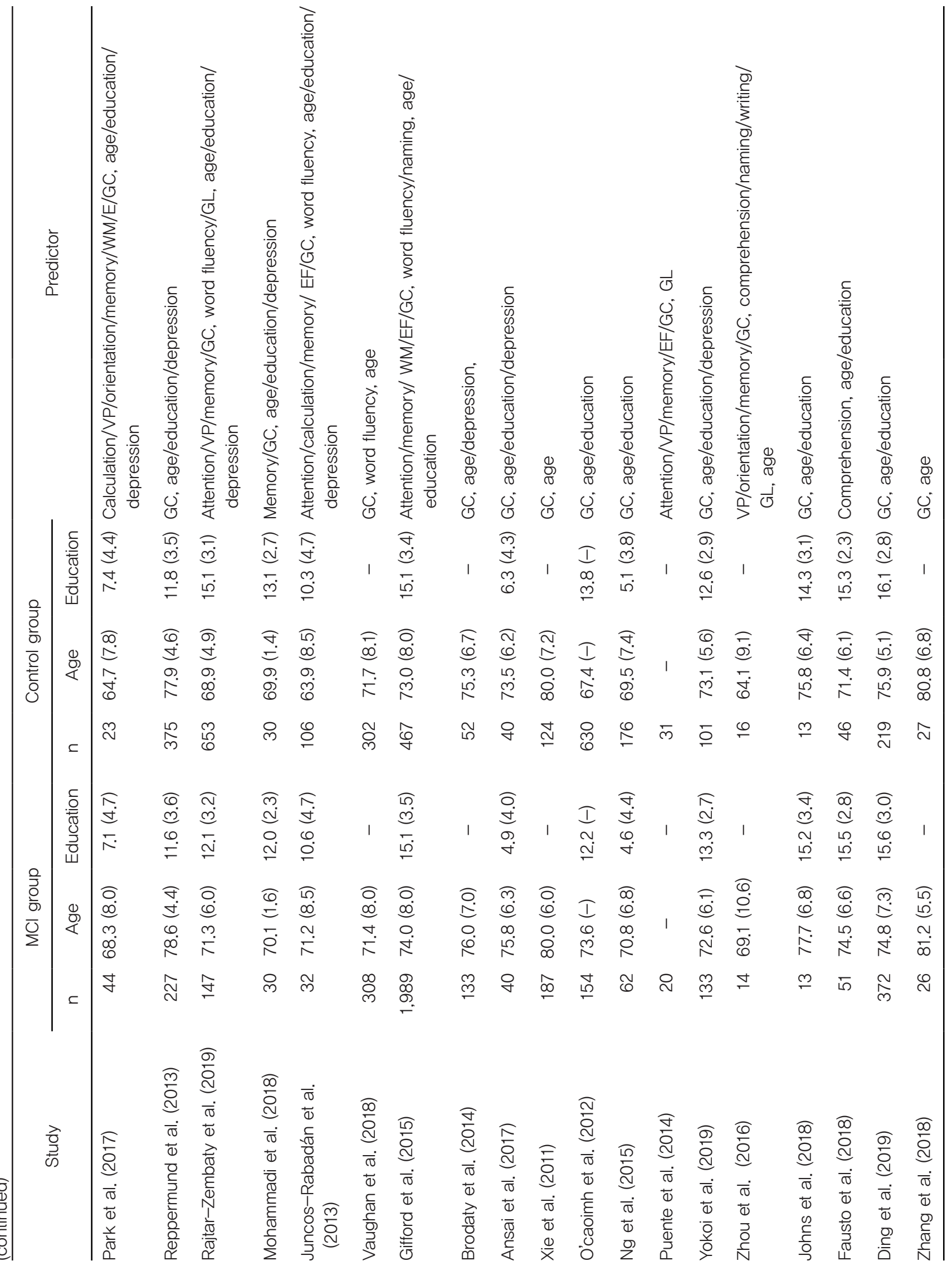




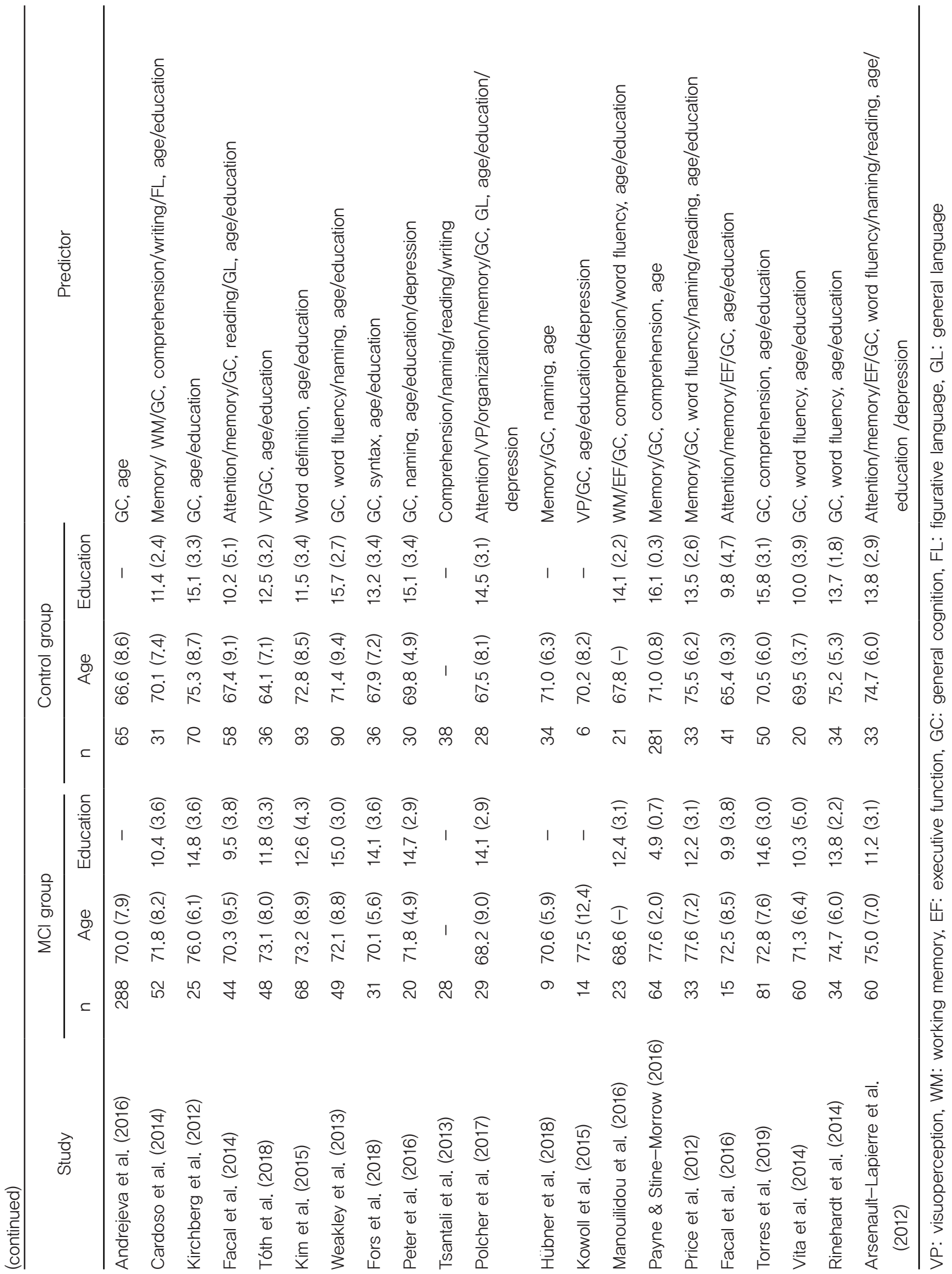




\section{Appendix 2. Lists of Studies Included in the Meta-Analysis}

\begin{tabular}{|c|c|}
\hline \multicolumn{2}{|r|}{ Study } \\
\hline Aguilar-Navarro et al.(2017) & $\begin{array}{l}\text { Clinical and demographic predictors of conversion to dementia in Mexican elderly with } \\
\text { mild cognitive impairment. Revista de Investigacion Clinica, 69(1), 33-39. }\end{array}$ \\
\hline Tokuchi et al.(2014) & $\begin{array}{l}\text { Clinical and demographic predictors of mild cognitive impairment for converting to } \\
\text { Alzheimer's disease and reverting to normal cognition. Journal of the Neurological } \\
\text { Sciences, 346(1-2), 288-292. }\end{array}$ \\
\hline Sachdev et al.(2013) & $\begin{array}{l}\text { Factors predicting reversion from mild cognitive impairment to normal cognitive } \\
\text { functioning: A population-based study. PloS one, 8(3), e59649. }\end{array}$ \\
\hline Kang et al.(2014) & $\begin{array}{l}\text { Factors associated with cognition recovery among elders with mild cognitive impairment } \\
\text { in Korea. International Nursing Review, 61(3), 318-326. }\end{array}$ \\
\hline Egli et al.(2015) & $\begin{array}{l}\text { Varying strength of cognitive markers and biomarkers to predict conversion and } \\
\text { cognitive decline in an early-stage-enriched mild cognitive impairment sample. } \\
\text { Journal of Alzheimer's Disease, 44(2), 625-633. }\end{array}$ \\
\hline Sheardova et al.(2014) & $\begin{array}{l}\text { Famous landmark identification in amnestic mild cognitive impairment and Alzheimer's } \\
\text { disease. PloS one, 9(8), e105623. }\end{array}$ \\
\hline Pandya et al.(2017) & $\begin{array}{l}\text { Predictors of reversion from mild cognitive impairment to normal cognition. Dementia and } \\
\text { Geriatric Cognitive Disorders, 43(3-4), 204-214. }\end{array}$ \\
\hline Dodge et al.(2015) & $\begin{array}{l}\text { Social markers of mild cognitive impairment: Proportion of word counts in free } \\
\text { conversational speech. Current Alzheimer Research, 12(6), 513-519. }\end{array}$ \\
\hline Albert et al.(2018) & $\begin{array}{l}\text { Predicting progression from normal cognition to mild cognitive impairment for individuals } \\
\text { at } 5 \text { years. Brain, } 141(3), 877-887 \text {. }\end{array}$ \\
\hline Cui et al.(2012) & $\begin{array}{l}\text { Predicting the development of mild cognitive impairment: A new use of pattern } \\
\text { recognition. Neurolmage, } 60 \text { (2), } 894-901 .\end{array}$ \\
\hline Ellendt et al.(2017) & $\begin{array}{l}\text { Predicting stability of mild cognitive impairment (MCI): Findings of a community based } \\
\text { sample. Current Alzheimer Research, 14(6), 608-619. }\end{array}$ \\
\hline Stormoen et al.(2014) & $\begin{array}{l}\text { Cognitive predictors of medical decision-making capacity in mild cognitive impairment } \\
\text { and Alzheimer's disease. International Journal of Geriatric Psychiatry, 29(12), 1304- } \\
1311 .\end{array}$ \\
\hline Thomas et al.(2018) & $\begin{array}{l}\text { Word-list intrusion errors predict progression to mild cognitive impairment. } \\
\text { Neuropsychology, 32(2), } 235-245 \text {. }\end{array}$ \\
\hline Pereira et al.(2018) & $\begin{array}{l}\text { Neuropsychological predictors of conversion from mild cognitive impairment to } \\
\text { Alzheimer's disease: A feature selection ensemble combining stability and predictability. } \\
\text { BMC Medical Informatics and Decision Making, } 18(1), 137 \text {. }\end{array}$ \\
\hline Alves et al.,(2018) & $\begin{array}{l}\text { Neuropsychological predictors of long-term (10 years) mild cognitive impairment stability. } \\
\text { Journal of Alzheimer's Disease, 62(4), 1703-1711. }\end{array}$ \\
\hline Shimada et al.(2019) & $\begin{array}{l}\text { Reversible predictors of reversion from mild cognitive impairment to normal cognition: A } \\
\text { 4-year longitudinal study. Alzheimer's Research and Therapy, 11(1), } 24 \text {. }\end{array}$ \\
\hline Kim et al.(2019) & $\begin{array}{l}\text { Data-driven prognostic features of cognitive trajectories in patients with amnestic mild } \\
\text { cognitive impairments. Alzheimer's Research and Therapy, 11(1), } 10 .\end{array}$ \\
\hline Park et al.(2017) & $\begin{array}{l}\text { Memory performance on the story recall test and prediction of cognitive dysfunction } \\
\text { progression in mild cognitive impairment and Alzheimer's dementia. Geriatrics and } \\
\text { Gerontology International, 17(10), 1603-1609. }\end{array}$ \\
\hline
\end{tabular}


(continued)

Study

\begin{tabular}{|c|c|}
\hline Reppermund et al.(2013) & $\begin{array}{l}\text { Impairment in instrumental activities of daily living with high cognitive demand is an early } \\
\text { marker of mild cognitive impairment: The Sydney Memory and Ageing Study. } \\
\text { Psychological Medicine, 43(11), 2437-2445. }\end{array}$ \\
\hline Rajtar-Zembaty et al.(2019) & $\begin{array}{l}\text { Global cognitive functioning and physical mobility in older adults with and without mild } \\
\text { cognitive impairment: evidence and implications. Folia Medica Cracoviensia, 59(1), } \\
75-88 \text {. }\end{array}$ \\
\hline Mohammadi et al.(2018) & $\begin{array}{l}\text { Using virtual reality to distinguish subjects with multiple- but not single-domain amnestic } \\
\text { mild cognitive impairment from normal elderly subjects. Psychogeriatrics, 18(2), 132- } \\
142 .\end{array}$ \\
\hline $\begin{array}{l}\text { Juncos-Rabadán et al. } \\
\text { (2013) }\end{array}$ & $\begin{array}{l}\text { Does tip-of-the-tongue for proper names discriminate amnestic mild cognitive } \\
\text { impairment? International Psychogeriatrics, 25(4), 627-634. }\end{array}$ \\
\hline Vaughan et al.(2018) & $\begin{array}{l}\text { Semantic and phonemic verbal fluency discrepancy in mild cognitive impairment: } \\
\text { Potential predictor of progression to Alzheimer's disease. Journal of the American } \\
\text { Geriatrics Society, 66(4), 755-759. }\end{array}$ \\
\hline Gifford et al.(2015) & $\begin{array}{l}\text { Inclusion of an informant yields strong associations between cognitive complaint and } \\
\text { longitudinal cognitive outcomes in non-demented elders. Journal of Alzheimer's } \\
\text { Disease, } 43(1), 121-132 \text {. }\end{array}$ \\
\hline Brodaty et al.(2014) & $\begin{array}{l}\text { Progression from mild cognitive impairment to dementia: A 3-year longitudinal study. } \\
\text { Australian and New Zealand Journal of Psychiatry, 48(12), 1137-1142. }\end{array}$ \\
\hline Ansai et al.(2017) & $\begin{array}{l}\text { Cognitive correlates of timed up and go subtasks in older people with preserved } \\
\text { cognition, mild cognitive impairment, and Alzheimer's disease. American Journal of } \\
\text { Physical Medicine and Rehabilitation, 96(10), 700-705. }\end{array}$ \\
\hline Xie et al.(2011) & $\begin{array}{l}\text { Identifying and characterizing trajectories of cognitive change in older persons with mild } \\
\text { cognitive impairment. Dementia and Geriatric Cognitive Disorders, } 31(2), 165-172 .\end{array}$ \\
\hline O'caoimh et al.(2012) & $\begin{array}{l}\text { Comparison of the quick mild cognitive impairment (Qmci) screen and the SMMSE in } \\
\text { screening for mild cognitive impairment. Age and Ageing, 41(5), 624-629. }\end{array}$ \\
\hline Ng et al.(2015) & $\begin{array}{l}\text { Montreal Cognitive Assessment for screening mild cognitive impairment: Variations in test } \\
\text { performance and scores by education in Singapore. Dementia and Geriatric Cognitive } \\
\text { Disorders, 39(3-4), 176-185. }\end{array}$ \\
\hline Puente et al.(2014) & $\begin{array}{l}\text { Functional impairment in mild cognitive impairment evidenced using performance-based } \\
\text { measurement. Journal of Geriatric Psychiatry and Neurology, 27(4), 253-258. }\end{array}$ \\
\hline Yokoi et al.(2019) & $\begin{array}{l}\text { Discrete effect of each mild behavioural impairment category on dementia conversion or } \\
\text { cognitive decline in patients with mild cognitive impairment. Psychogeriatrics, 19(6), } \\
591-600 .\end{array}$ \\
\hline Zhou et al. (2016) & $\begin{array}{l}\text { Characteristics of agraphia in Chinese patients with Alzheimer's disease and amnestic } \\
\text { mild cognitive impairment. Chinese Medical Journal, 129(13), 1553-1557. }\end{array}$ \\
\hline Johns et al.(2018) & $\begin{array}{l}\text { Cognitive modeling as an interface between brain and behavior: Measuring the semantic } \\
\text { decline in mild cognitive impairment. Canadian Journal of Experimental } \\
\text { Psychology/Revue Canadienne de Psychologie Expérimentale, 72(2), 117-126. }\end{array}$ \\
\hline Fausto et al.(2018) & $\begin{array}{l}\text { Comparison of subjective and objective measures of hearing, auditory processing, and } \\
\text { cognition among older adults with and without mild cognitive impairment. Journal of } \\
\text { Speech, Language, and Hearing Research, 61(4), 945-956. }\end{array}$ \\
\hline
\end{tabular}


(continued)

\begin{tabular}{|c|c|}
\hline \multicolumn{2}{|r|}{ Study } \\
\hline Ding et al.(2019) & $\begin{array}{l}\text { Evaluating trajectories of episodic memory in normal cognition and mild cognitive } \\
\text { impairment: Results from ADNI. PLoS One, 14(2), e0212435. }\end{array}$ \\
\hline Zhang et al.(2018) & $\begin{array}{l}\text { Evaluation of MESSAGE communication strategy combined with group reminiscence } \\
\text { therapy on elders with mild cognitive impairment in long-term care facilities. } \\
\text { International Journal of Geriatric Psychiatry, 33(4), 613-622. }\end{array}$ \\
\hline Andrejeva et al.(2016) & $\begin{array}{l}\text { Neurocognitive deficits and effects of cognitive reserve in mild cognitive impairment. } \\
\text { Dementia and Geriatric Cognitive Disorders, 41(3-4), 199-209. }\end{array}$ \\
\hline Cardoso et al.(2014) & $\begin{array}{l}\text { Non-literal language deficits in mild cognitive impairment. Psychogeriatrics, 14(4), 222- } \\
228 .\end{array}$ \\
\hline Kirchberg et al.(2012) & $\begin{array}{l}\text { Semantic distance abnormalities in mild cognitive impairment: Their nature and } \\
\text { relationship to function. The American Journal of Psychiatry, 169(12), 1275-1283. }\end{array}$ \\
\hline Facal et al.(2014) & $\begin{array}{l}\text { Working memory span in mild cognitive impairment. Influence of processing speed and } \\
\text { cognitive reserve. International Psychogeriatrics, 26(4), 615-625. }\end{array}$ \\
\hline Tóth et al.(2018) & $\begin{array}{l}\text { A speech recognition-based solution for the automatic detection of mild cognitive } \\
\text { impairment from spontaneous speech. Current Alzheimer Research, 15(2), 130-138. }\end{array}$ \\
\hline Kim et al.(2015) & $\begin{array}{l}\text { Abstract word definition in patients with amnestic mild cognitive impairment. Behavioural } \\
\text { Neurology, } 2015,580246 \text {. }\end{array}$ \\
\hline Weakley et al.(2013) & $\begin{array}{l}\text { Analysis of verbal fluency ability in amnestic and non-amnestic mild cognitive } \\
\text { impairment. Archives of Clinical Neuropsychology, 28(7), 721-731. }\end{array}$ \\
\hline Fors et al.(2018) & $\begin{array}{l}\text { Automated syntactic analysis of language abilities in persons with mild and subjective } \\
\text { cognitive impairment. Studies in Health Technology and Informatics, 247, 705-709. }\end{array}$ \\
\hline Peter et al.(2016) & $\begin{array}{l}\text { Category and design fluency in mild cognitive impairment: Performance, strategy use, } \\
\text { and neural correlates. Neuropsychologia, 93(pt A), 21-29. }\end{array}$ \\
\hline Tsantali et al.(2013) & $\begin{array}{l}\text { Could language deficits really differentiate mild cognitive impairment (MCl) from mild } \\
\text { Alzheimer's disease? Archives of Gerontology and Geriatrics, 57(3), 263-270. }\end{array}$ \\
\hline Polcher et al.(2017) & $\begin{array}{l}\text { Face-name associative recognition deficits in subjective cognitive decline and mild } \\
\text { cognitive impairment. Journal of Alzheimer's Disease, 56(3), 1185-1196. }\end{array}$ \\
\hline Hübner et al.(2018) & $\begin{array}{l}\text { Naming and verbal learning in adults with Alzheimer's disease, mild cognitive impairment } \\
\text { and in healthy aging, with low educational levels. Arquivos de Neuro-Psiquiatria, 76(2), } \\
\text { 93-99. }\end{array}$ \\
\hline Kowoll et al.(2015) & $\begin{array}{l}\text { Neuropsychological profiles and verbal abilities in lifelong bilinguals with mild cognitive } \\
\text { impairment and Alzheimer's disease. Journal of Alzheimer's Disease, 45(4), 1257-1268. }\end{array}$ \\
\hline Manouilidou et al.(2016) & $\begin{array}{l}\text { Processing complex pseudo-words in mild cognitive impairment: The interaction of } \\
\text { preserved morphological rule knowledge with compromised cognitive ability. Clinical } \\
\text { Linguistics and Phonetics, 30(1), 49-67. }\end{array}$ \\
\hline $\begin{array}{l}\text { Payne \& Stine-Morrow } \\
\text { (2016) }\end{array}$ & $\begin{array}{l}\text { Risk for mild cognitive impairment is associated with semantic integration deficits in } \\
\text { sentence processing and memory. The journals of gerontology. Series B, Psychological } \\
\text { Sciences and Social Sciences, 71(2), 243-253. }\end{array}$ \\
\hline Price et al.(2012) & $\begin{array}{l}\text { Semantic verbal fluency strategies in amnestic mild cognitive impairment. } \\
\text { Neuropsychology, 26(4), 490-497. }\end{array}$ \\
\hline Facal et al.(2016) & $\begin{array}{l}\text { Temporal changes in semantic and lexical access related to mild cognitive impairment. } \\
\text { Aging Clinical and Experimental Research, 28(3), 497-504. }\end{array}$ \\
\hline
\end{tabular}


(continued)

Study

\begin{tabular}{l|l}
\hline Torres et al.(2019) & $\begin{array}{l}\text { Types of errors on a semantic interference task in mild cognitive impairment and } \\
\text { dementia. Neuropsychology, 33(5), 670-684. }\end{array}$ \\
\hline Vita et al.(2014) & $\begin{array}{c}\text { Typicality of words produced on a semantic fluency task in amnesic mild cognitive } \\
\text { impairment: Linguistic analysis and risk of conversion to dementia. Journal of } \\
\\
\text { Alzheimer's Disease, 42(4), 1171-1178. }\end{array}$ \\
\hline Rinehardt et al.(2014) & Verbal fluency patterns in mild cognitive impairment and Alzheimer's disease. Dementia \\
& and Geriatric Cognitive Disorders, 38(1-2), 1-9. \\
\hline Arsenault-Lapierre et al. & Word reading threshold and mild cognitive impairment: A validation study. BMC \\
(2012) & Geriatrics, 12, 38. \\
\hline
\end{tabular}

Appendix 2 문헌의 순서는 Appendix 1 목록의 순서대로 기재되었다. 